\title{
Prediction of Structural Response of Naval Vessels Based on Available Structural Health Monitoring Data
}

\author{
Alysson Mondoro ${ }^{1}$, Mohamed Soliman ${ }^{2}$, Dan M. Frangopol ${ }^{3, *}$
}

\begin{abstract}
Structural health monitoring (SHM) can be beneficial in reducing epistemic uncertainties associated with fatigue life prediction. For naval ships, available SHM data can be discretized into operational cells, each referring to a certain navigation speed, heading angle, and sea condition. Cell-based approaches for predicting future fatigue life can be applied if monitoring information is known for all cells. However, the available SHM data may populate some, but not all, potential cells. Moreover, since SHM data is only available for a given set of operating conditions, potential changes in climate or operational profiles cannot be accounted for. Accordingly, there is a need for an approach to predict structural responses in unmonitored cells as a function of limited available monitoring data. This paper proposes a methodology to predict the responses of naval vessels in unobserved cells by incorporating data from the limited number of observed cells. The power spectral density (PSD) of the SHM data is fit using generalized fitting functions, based on sea wave spectra, and integrated into the prediction of the PSD for unobserved cells. The proposed methodology enables both spectral and time-domain fatigue methods. The proposed methodology is illustrated on the SHM data from a high speed aluminum catamaran.
\end{abstract}

Keyword: Fatigue, Aluminum Vessels, Structural Health Monitoring, Ocean Wave Spectra, Power Spectral Density.

\footnotetext{
${ }^{1}$ Graduate Research Assistant, Department of Civil and Environmental Engineering, ATLSS Engineering Research Center, Lehigh University, 117 ATLSS Dr., Bethlehem, PA 18015-4729, alm312@lehigh.edu

${ }^{2}$ Assistant Professor, School of Civil and Environmental Engineering, College of Engineering, Architecture and Technology, Oklahoma State University, 207 Engineering South, Stillwater, OK 74078-5033 mohamed.soliman@okstate.edu

${ }^{3}$ Professor and the Fazlur R. Khan Endowed Chair of Structural Engineering and Architecture, Department of Civil and Environmental Engineering, ATLSS Engineering Research Center, Lehigh University, 117 ATLSS Dr., Bethlehem, PA 18015-4729, dan.frangopol@lehigh.edu.

${ }^{*}$ Corresponding Author, dan.frangopol@lehigh.edu.
} 


\section{Introduction}

Structural health monitoring (SHM) has recently been integrated into the life-cycle performance assessment program of the U.S. Navy (Sielski 2012) in an effort to monitor the performance of high-speed, high-performance naval vessels. In both civil and naval structures, SHM data are useful for the detection and diagnosis of damage at various locations throughout the structure (Herszberg et al. 2005; Okasha et al. 2011; Reed and Earls 2015; Vanik et al. 2000). SHM data can provide information regarding the initial as-built condition of the structure, the actual loads acting on the structure, and, if damage occurs, the current state of the structure. Currently, research efforts have been made to incorporate SHM data into service life predictions of naval ships (Soliman et al. 2015; Nichols et al. 2014).

Fatigue damage in aluminum naval vessels is a major concern. This is due to the high propagation rate of cracks in aluminum details and the considerable cost and effort associated with the repair process of damaged hulls. Deficiencies in fatigue damage prediction models are addressed, in part, through the use of SHM data. SHM directly contains considerations on the operational loads the ship is subjected to, as well as the as-built characteristics of the ship (Lynch and Loh 2006); thus, epistemic uncertainties associated with load effects can be significantly reduced. Performance updating (e.g., using the Bayesian approach) has also been employed to integrate SHM data into structural predictions of ship performance parameters, such as vertical bending moments and fatigue life estimates, to account for the stochastic nature of the loads and structural materials (Okasha et al. 2010; Ling et al. 2011; Zárate et al. 2012). The use of observed SHM data in future service life predictions and management strategies dictates the assumption that future loading conditions are similar to past ones (Soliman et al. 2015). This leads to a distinct issue when the operational profile changes. The recent increase in the operational rate and required 
service life of the vessels operated by the U.S. Navy exemplifies one of these potential changes. Additionally, global climate change may increase the occurrence rate of intense storms (McCarthy 2001) and, consequently, exemplifies another potential change in the operational profile. As a result, vessels operated in these future conditions can experience a larger number of annual cycles and may be exposed to rougher and more extreme seas. Thus, the assumption of past data being indicative of future loads and loading sequences is not always valid.

The lifetime weighted sea method (Hughes 1983) is used to predict the lifetime load effects for potential future loading sequences. Potential operational conditions are categorized by ship speed, heading angle, and sea state into cells with different probabilities of occurrence based on location and ship routes. These probabilities are developed based on wave scatter diagrams and vary based on location (Hughes 1983, Kahma et al 2003). The lifetime load effect is then computed as the summation of the load effect in each cell, weighted by the probability of operating in that cell. In these approaches, SHM information provides a measure of fatigue load effects associated with each operational cell. Previous efforts to include SHM data to reduce epistemic uncertainties in fatigue life assessment rely heavily on past operational conditions and not on future operational profiles. Future operational profiles may include exposure to cells not previously recorded. This represents a major deficiency in current SHM-based fatigue life estimation methodologies which is directly addressed in this paper.

The lifetime structural response of the ship hull to all sea states, heading angles, and speeds is a nonstationary random process. However, when the observed data is discretized by the aforementioned quantities into cells, observed SHM data in each cell can be considered as a stationary process (Naess and Moan 2012). A full sampling of all potential cells during SHM observations is unlikely due to time restrictions and weather conditions, especially if discrete 
monitoring practices are in place. An approach which enables predicting the hull response in missing cells, with the goal of developing the full set of SHM data that is necessary for fatigue damage assessment, is still needed.

Data extrapolation techniques for ship response have been developed around cell parameters (i.e., heading angle, ship speed, and sea wave height) and the response parameter of interest (e.g., fatigue damage accumulation). Zhu (2014) proposed a linear interpolation method for identifying the statistical descriptors of vertical bending moments with respect to synthetic data generated using the Large Amplitude Motion Program. This synthetic data does not include information on the as-built condition of the ship or observed loads.

SHM data consists of the recorded time-history of an observed response (e.g., strain and acceleration). The power spectral density (PSD) function is a representation of the same signal in the frequency domain. The PSD function defines the signal energy as a function of the different frequency components. In the design stage, the PSD is determined from the response amplitude operator and the power spectra of the wave heights. An observed PSD, however, can be directly calculated from the SHM data. The observed PSD includes low frequency content, high frequency content, and noise. By developing the PSD for the full set of cells through the prediction method proposed herein, spectral based methods for fatigue assessment can be directly implemented to estimate the damage accumulation through Miner's law (Bendat 1964; Dirlik 1985; Lutes and Larsen 1990). Moreover, time domain predictions can be performed to estimate fatigue damage by generating an instance of the random process, using cycling counting methods to determine the stress range, and then applying Miner's rule. In both cases, the contributions of the low frequency and high frequency response components to the stress range distribution and subsequent fatigue assessment are captured. 
This paper presents a methodology for using the SHM data recorded in observed operational cells to estimate the response in unobserved cells. The approach integrates SHM data from sea keeping trials in order to quantify and reduce uncertainties in the prediction of structural response and can be applied to enhance the accuracy of fatigue life estimation of ship details. The approach is capable of capturing the low and high frequency response and using it in fatigue damage predictions. Fitting functions for the PSD of observed responses are proposed for both the low frequency and high frequency content of the signal. The proposed methodology fits the observed PSD with functions based on accepted forms for sea wave spectra and investigates their applicability. The fitting is performed piece-wise: the low frequency content is fitted first, then the high frequency content is fitted, and finally summed together for the complete PSD. The estimated parameters for unobserved cells are predicted and a synthetic power spectral density function is developed. By developing the PSD for the full set of cells, both frequency domain and time domain predictions can be performed to estimate fatigue damage. The proposed methodology is applied to the SHM data from the seakeeping trials of the HSV-2 Swift, a $98 \mathrm{~m}$ (322 ft), high-speed, aluminum catamaran.

\section{Ship Response}

A naval vessel is exposed to various loading conditions throughout its lifetime based on its operational theatre and routes. As a result, the time-history response of the ship is a nonstationary random process for which the life-cycle performance is difficult to assess. The nonstationary timehistory can be divided into smaller, stationary processes based on operating conditions such as wave height, vessel speed, and heading angle. For a given operational profile, the lifetime sustained loads and load effects can then be built up with additional information on the wave scatter 
diagram (Sikora et al. 1983). The lifetime weighted sea method uses the response in each of the stationary cells to evaluate the long term performance (Hughes 1983).

Structural performance assessment can be performed in either the time domain or the frequency domain. For frequency-based methods, the structural time-history response is analyzed in the frequency domain and represented with a response spectrum. The response spectrum is a function of both the loading conditions (i.e., the random sea waves) and the structural response. In this paper, linear waves are considered and the loading conditions are defined by the sea wave spectrum, $S_{\xi}(\omega)$, which accounts for the development state of the wave, sea floor topology, fetch limitations, and local currents and swells, among others (Komen et al. 1984). The response spectrum, $S_{R}(\omega)$, is found through the use of a transfer function applied to the loading spectrum. In the case of the structural response of naval vessels to linear waves, the response amplitude operator $R_{A}(\omega)$ is used as the linear transfer function, and is different for each cell (Naess and Moan 2012). Accordingly, the response spectrum, $S_{R}(\omega)$, is expressed as

$$
S_{R}(\omega)=\left[R_{A}(\omega)\right]^{2} S_{\xi}(\omega)
$$

Characterizing the sea surface and wave heights is a highly investigated field with multiple analytical and experimentally developed forms capable of representing the sea wave spectrum $S_{\xi}(\omega)$. This paper considers two commonly used spectra: Pierson-Moskowitz and Joint North Sea Wave Observation Project (JONSWAP). The Pierson-Moskowitz wave spectrum is for fully developed seas wherein the waves have come to equilibrium with the wind (Pierson Jr and Moskowitz 1963). The single sided Pierson-Moskowitz spectrum is

$$
S_{P M}^{+}(\omega)=\frac{\alpha g^{2}}{\omega^{5}} \exp \left(-\frac{5}{4}\left(\frac{\omega}{\Omega}\right)^{-4}\right)
$$


where $\alpha$ is $8.10 \times 10^{-3}, g$ is the gravitational constant $\left(9.81 \mathrm{~m} / \mathrm{s}^{2}\right)$, and $\Omega$ is the wave frequency. However, this spectrum fails to fully capture the peak responses for waves that are not fully developed or are fetch limited. The JONSWAP investigated the sea surface in the North Sea, were the waves were either partially formed or experienced wave-wave interactions (Hasselmann et al. 1973). The resulting JONSWAP spectrum modifies the Pierson-Moskowitz spectrum with a peak enhancement factor, $\gamma$

$$
S_{\text {JONSWAP }}^{+}(\omega)=\frac{\alpha g^{2}}{\omega^{5}} \exp \left(-\frac{5}{4}\left(\frac{\omega}{\Omega}\right)^{-4}\right) \gamma^{\exp \left(-\frac{(\omega-\Omega)^{2}}{2 \Omega^{2} \sigma^{2}}\right)}
$$

where

$$
\sigma= \begin{cases}0.7 & \text { if } w \leq \Omega \\ 0.9 & \text { if } w>\Omega\end{cases}
$$

The response amplitude operator, $R_{A}(\omega)$, is developed on a cell-by-cell basis as the response of the ship is dependent on the heading angle, sea state, and vessel speed. $R_{A}(\omega)$ is the structural response (i.e., stress, strain, or accelerations at a given point in the structure) to a unit sinusoid at each frequency. Typically, linear structural analysis methods are employed to determine the stresses, used in fatigue life estimation, due to vertical bending induced by waves. Linear strip theory can be used to quantify vertical bending moment for head seas condition at zero speed, which can be modified for different heading angles and speeds to generate other $R_{A}(\omega)$ functions (Sikora 1998). However, in some cells, nonlinear structural analysis may be required either due to the presence of combined wave and slam response (Sikora et al. 2002) or material and geometric nonlinearities. Through the application of nonlinear quadratic strip theory, Jensen and Dogliani (1996) demonstrated that the nonlinear contributions are at least as important as the linear 
contributions. Commercial analysis tools are available for the bending response to waves but are not readily available to analyze whipping response (Tuitman 2010).

Fatigue life is shown to be dependent on both the low frequency response due to waves and the high frequency response due to slamming. In this way, the lack of commercially available tools represents a limitation in the application of lifetime weighted sea method for fatigue life estimation. This paper proposes the use of a fitting function for the spectral response determined from SHM data. The fitting functions are formulated around the sea wave spectrum and quantified for each observed cell of the SHM in order to predict the spectral response to unobserved cells.

Generalized variations of the Pierson-Moskowitz spectrum and the JONSWAP spectrum are proposed in Eqs. (5) and (6), respectively, as potential fitting functions for the observed PSD functions of the monitored structural detail

$$
\begin{gathered}
S_{P M_{g e n}}^{+}(\omega)=\frac{A}{\omega^{5}} e^{-B \omega^{-4}} \\
S_{\text {JONSWAP }}^{+}(\omega)=\frac{C}{\omega^{5}} \exp \left(-\frac{5}{4} D^{4} \omega^{-4}\right) E^{\exp \left(-\frac{(\omega-D)^{2}}{2 D^{2} \sigma^{2}}\right)}
\end{gathered}
$$

where $A$ and $B$ are fitting coefficients for the generalized Pierson-Moskowitz function and $C, D$, and $E$ are fitting coefficients for the generalized JONSWAP function. The SHM data include the low and high frequency content of the structural response that are essential to fatigue life predictions. Thus, the proposed fitting functions are expanded to consider the low frequency and high frequency response components. The complete fitting functions for the observed single-sided PSD functions of the monitored structural detail take the form

$$
\begin{aligned}
& S_{P M_{G E N}}^{+}(\omega)=\frac{A_{L F}}{\omega^{5}} e^{-B_{L F} \omega^{-4}}+\frac{A_{H F}}{\omega^{5}} e^{-B_{H F} \omega^{-4}}
\end{aligned}
$$

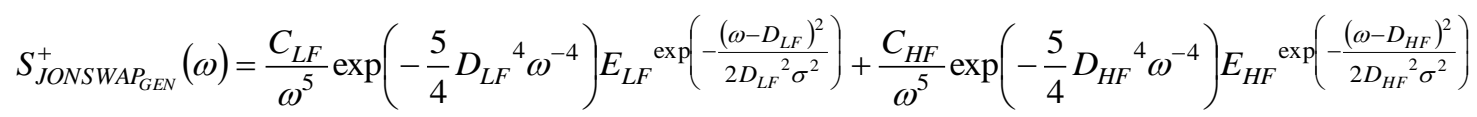


where $A_{L F}$ and $B_{L F}$ are fitting coefficients for the low frequency content and $A_{H F}$ and $B_{H F}$ are fitting coefficients for the high frequency content of the complete generalized Pierson-Moskowitz function, $S_{P M_{G E}}^{+}$; and $C_{L F}, D_{L F}$, and $E_{L F}$ are the fitting coefficients for the low frequency content and $C_{H F}, D_{H F}$, and $E_{H F}$ are fitting coefficients for the high frequency content of the complete generalized JONSWAP function, $S_{J O N S W A P_{G E N}}^{+}$.

\section{Data Prediction}

Missing data is a significant problem in SHM. Instrument failure, power interruptions, and erroneous measurements create gaps in recorded data (Posenato et al. 2010). Additionally, discrete monitoring practices inherently omit samples of data. The application of data mining techniques, such as neural networks, have been applied to missing data problems in SHM (Chang et al. 2003). Neural networks map given input parameters to response characteristics based on training information (Liu and Nayak 2012). Since the performance and accuracy of neural networks lies within the range of the training data, it is not widely applicable as an extrapolation method (Lohninger 1999). Alternatively, linear response surfaces have been employed to extrapolate probabilistic descriptors of the vertical bending moment response in Zhu (2014). This paper proposes the use of a linear function for each of the parameters in the PSD fitting functions as

$$
\Psi_{i}=p_{1, i} S H+p_{2, i} V+p_{3, i} \alpha
$$

where $S H$ is the sea wave height, $V$ is the ship velocity, $\alpha$ is the heading angle, and $\Psi_{i}$ is element $i$ of the set $\boldsymbol{\Psi}=\left\{A_{L F}, B_{L F}, A_{H F}, B_{H F}, C_{L F}, D_{L F}, E_{L F}, C_{H F}, D_{H F}, E_{H F}\right\}$.

In order to investigate the effect of the interpolation function on the response prediction from incomplete dataset, a generic stress range dataset has been defined as shown in Fig. 1. This dataset provides the stress range at several values of ship speed and sea wave height for head seas 
(i.e. $\alpha=0^{\circ}$ ). The data is defined to reflect real situations where the stress range would increase with both the wave height and the navigation speed. Stress range data is fitted with a linear and quadratic fitting functions. The effect of available data on the linear and quadratic functions is shown in Fig. 1. Fig. 1a includes the fitted functions for a linear fit for the generic set of stress range data with $100 \%$ and $50 \%$ of the data. Alternatively, Fig. 1b depicts the quadratic function fitted with $100 \%$, and $50 \%$ of the data. The $50 \%$ data set includes the lightly colored points and the $100 \%$ data set includes both the lightly colored and black points. The quadratic function fitted for $100 \%$ of the data predicts an increase in the stress range as both sea wave height and speed increase. However, when only $50 \%$ of the data is used to develop the extrapolation function, low stress range values are predicted at high sea wave heights and speeds. The linear function extrapolates values more consistently with the extrapolation functions developed from both $50 \%$ and $100 \%$ data predicting larger values of stress ranges at high sea wave heights and speeds. For this application, the monotonic linear function provides a more robust extrapolation technique as compared to higher order estimates. Theoretical dependencies of predicted field quantities on wave height, heading angle, or ship speed could be integrated into future work but are not included in this paper.

\section{Fatigue Life Assessment}

Fatigue has been identified as one of the major thrust area of research for high-speed, highperformance naval vessels (Sielski et al. 2013). Fatigue damage on ships is a direct result of the constantly fluctuating sea waves and the associated loading cycles. Fatigue causes gradual accumulation of damage due to repeated load variations. Damage indices are useful in quantifying

the state of fatigue damage of a ship as a function in time. However, if a more detailed representation of the fatigue damage state is required, fracture mechanics models may be used. 
Fracture mechanics models define the development of fatigue cracks in three stages: (1) crack initiation, (2) linear crack growth, and (3) the nonlinear crack growth region. This paper focuses on the damage indices and their formulation in both the frequency and time domains.

The codified procedures widely implement the stress-life (S-N) approach for fatigue assessment (DNV 2010; Eurocode 9 2009). Stress-life curves relate stress ranges to the number of cycles to failure for a given structural detail. Fatigue damage indices have been introduced to quantify damage state of a given structural detail as a function of the amount of cycles spent under a particular loading history. Miner's linear damage accumulation index is an example of these indices which quantifies the state of damage for the structural detail and is expressed as

$$
D=\sum_{i=1}^{n_{s s}} \frac{n_{i}}{N_{i}}
$$

where $n_{s s}$ is the number of stress range bins in a stress histogram, $n_{i}$ is the number of stress cycles in $i^{\text {th }}$ bin with stress range $S_{i}$, and $N_{i}$ is the number of cycles to failure under $S_{i}$. For a linear S-N curve, the number of cycles to failure is calculated as

$$
N=\frac{A}{S^{m}}
$$

where $A$ is the fatigue coefficient for the structural detail and $m$ is the slope of the S-N line in logarithmic scale. There is, however, no widely accepted value at which the structural detail is known to have failed.

In the time domain, the stress range histogram is found through applying cycle counting methods to the SHM data; the damage accumulation index is found directly through Eq. (10). For the frequency domain, significant research has been developed to estimate the damage accumulation index from the PSD function (Benasciutti and Tovo 2007). For stationary, Gaussian, 
narrow-banded processes where the stress ranges follow a Rayleigh distribution, the stress range histogram can be expressed as (Bendat 1964)

$$
N(S)=\sqrt{\frac{m_{4}}{m_{2}}} T\left(\frac{S}{4 m_{0}} \exp \left(-\frac{S^{2}}{g m_{0}}\right)\right)
$$

where $N$ is the number of cycles of stress range $S$ in $T$ seconds, and $m_{i}$ is the $i^{\text {th }}$ moment of area of the PSD function

$$
m_{n}=\int_{0}^{\infty} \omega^{n} S_{R}^{+}(\omega) d \omega
$$

where $S_{R}{ }^{+}$is the single sided response spectrum.

The solution found through the narrow-band approximation is extremely conservative as it is assumed that each peak has a corresponding trough with similar magnitude. In reality, the process is a wide-band or bi-modal process with high frequency waves super-imposed on low frequency waves; both contributing significantly to the fatigue damage. (Aalberts and Nieuwenhuijs 2006; Mao et al. 2010)

An approach to estimate the stress range histogram for wide-band Gaussian processes through extensive computational analyses was introduced by Dirlik (1985). The range mean histogram for a broad-band process is (Dirlik 1985)

$$
N(S)=E[P] \cdot T \cdot p(S)
$$

where

$$
p(S)=\frac{\frac{D_{1}}{Q} \exp \left(-\frac{Z}{Q}\right)+\frac{D_{2} Z}{R^{2}} \exp \left(-\frac{Z^{2}}{2 R^{2}}\right)+D_{3} Z \exp \left(-\frac{Z^{2}}{2}\right)}{2 \sqrt{m_{0}}}
$$

and 


$$
\begin{array}{ccc}
D_{1}=\frac{2\left(x_{m}-\gamma^{2}\right)}{1+\gamma^{2}} & D_{2}=\frac{1-\gamma-D_{1}+D_{1}^{2}}{1-R} & D_{3}=1-D_{1}-D_{2} \\
Q=\frac{1.25\left(\gamma-D_{3}-D_{2} R\right)}{D_{1}} & R=\frac{\gamma-x_{m}-D_{1}^{2}}{1-\gamma-D_{1}-D_{1}^{2}} & Z=\frac{S}{2 \sqrt{m_{0}}} \\
\gamma=\frac{m_{2}}{\sqrt{m_{0} m_{4}}} & x_{m}=\frac{m_{1}}{m_{0}} \sqrt{\frac{m_{2}}{m_{4}}} & E[P]=\sqrt{\frac{m_{4}}{m_{2}}}
\end{array}
$$

The resulting stress range histogram is shown to be comparable to the histogram developed through the cycle counting method (Wirsching and Shehata 1977). This paper integrates the three methods for estimating the stress range histograms discussed in this section: cycle-counting methods, Bendat's narrow-band approximations, and Dirlik's broad-band approximation. For a further estimation of the long term fatigue cumulative damage factor, the observed and predicted data can be coupled with the appropriate wave scatter diagram for the anticipated operational location.

\section{Generation of Random Processes}

Analyzing SHM data through the PSD function and predicting it in unobserved cells directly enables spectral based fatigue analysis in all cells that may be encountered in future operations. However, it also indirectly enables time domain methods; sample random processes can be generated from the PSD function and act as synthetic data for that cell. Time-history responses for unobserved cells are then readily available to be used in cycling counting methods.

The elevation of the sea surface is typically considered Gaussian (Butler et al. 2009). However, for larger waves, the shape of the wave deviates from a simple sinusoid and becomes cnoidal or otherwise Non-Gaussian (Osborne 2010). Even though waves of higher severity may 
be nonlinear, a linear wave assumption is often used in predicting extreme response (Ochi 1978; Kim 2008). This paper assumes linear waves. An assumption that was reinforced during the data processing stages when the SHM data was found to be Gaussian.

For low intensity operating conditions (i.e., low speeds and low wave heights) the distribution of the recorded strains, stresses, and other observed response of the ship is also Gaussian (Naess and Moan 2012). However, due to nonlinearities in material properties, fluidstructure interaction, or extreme seas, the response may become non-Gaussian (Jensen and Dogliani 1996). An initial investigation into the distribution of the SHM data is required before simulating the random process.

The spectral representation method is highly efficient and easily implemented for generating a realization of a Gaussian random process (Shinozuka and Deodatis 1991). For a stationary, ergodic, Gaussian random process $x(t)$, a realization of the random process is generated as a summation of sinusoids (Shinozuka and Deodatis 1991) as follows:

$$
x(t)=\sqrt{2} \sum_{n=0}^{P-1} \sqrt{S_{x x} \Delta \omega} \cos \left(\omega_{n} t+\Phi_{n}\right)
$$

where $S_{x x}$ is the single sided spectral density function, $\omega_{n}$ is $n \Delta \omega, \Delta \omega$ is $\omega_{u} / P, \omega_{u}$ is the cutoff frequency, $\Phi_{n}$ is uniform random from 0 to 1 . Since $\Phi_{n}$ are independently generated and $P$ approaches $\infty$, the generated sample is Gaussian through the central limit theorem. Reformulated to capitalize on the computational efficiency of the Fast Fourier Transform, Eq. (17) can be rewritten as

$$
x(p \Delta t)=\operatorname{Re}\left\{\sum_{n=0}^{M-1} B_{n} \exp (i(n \Delta \omega)(p \Delta t))\right\}
$$

where Re indicates the real part, $M \geq 2 P, p=0,1,2 \ldots \mathrm{M}-1, \Delta t \leq 2 \pi / 2 \omega_{u}$, and 


$$
B_{n}=\sqrt{2 S_{x x} \Delta \omega} \exp \left(i \Phi_{n}\right)
$$

While this paper restricts its fatigue assessment to methods based on damage indices, crack growth models provide alternative means of assessment. The proposed methodology for developing stress range histograms in unobserved cells can be directly integrated into linear crack growth models which are dependent on the stress range distributions. For nonlinear crack growth models, the strain time-histories of the loadings are necessary (Hodapp et al. 2015). The methodology proposed in this paper for predicting the PSD and generating a random process for unobserved cells applies to strain observations as well. Thus, in future work, the proposed methodology can be used to generate the synthetic strain histories needed to facilitate nonlinear crack growth predictions in the unobserved cells.

\section{Application}

The data fitting and prediction procedures detailed in Sections 2 to 5 are summarized in Fig. 2 and are applied to the SHM data from the HSV-2 Swift. The HSV-2 Swift is a 98 meter long aluminum vessel contracted by the U.S. Navy, designed by Revolution Design in Tasmania, Australia, and built by Incat Tasmania (Brady et al. 2004). The ship is equipped with a ride control system to stabilize motion at high speeds by deploying a T-foil. The HSV-2 Swift performed seakeeping trials and recorded SHM data and visual observations.

The HSV-2 Swift was instrumented by strain gauges and sensors that were connected to the shipboard systems. The shipboard systems, including the GPS and gyro systems, provided the track, course, and speed of the ship during operation. The sensor network was designed and implemented to capture the (a) primary load, (b) stress concentration, (c) secondary loads, and (d) ramp, crane, vehicle deck, helicopter deck, and gun mount responses. The primary load response sensors included 16 strain gauges located at optimal locations derived from finite element analysis 
models (Brady et al. 2004). The observed data were recorded and compared with predetermined limits and design loads. The stress concentration responses were determined through the conversion of strain gauge data collected from the T2 sensor group. The T2 sensors include 18 strain gauges installed at high-stress areas indicated in the FEA analysis results with the goal of providing stress data at fatigue critical details. The data collected from the T2-4 sensor during the HSV2-Swift trials when the T-foil was in a retracted state is used in this paper as the example of SHM data. The T2-4 sensor is located on frame 26 along the keel and is shown in Fig. 3. The data were collected at a sampling rate of $100 \mathrm{~Hz}$.

The HSV-2 Swift performed sea keeping trials in both calm and rough waters by moving at varying speeds and directions. The objective of the sea keeping trials was to observe the structural response for potential operating conditions. The vessel was operated at sustained speeds ranging from 2 to 35 knots in an octagonal pattern and recorded data for heading angles of $0^{\circ}, 45^{\circ}$, $60^{\circ}, 135^{\circ}, 180^{\circ}, 225^{\circ}, 270^{\circ}, 315^{\circ}$, and $360^{\circ}$. Data from the octagonal trials were stored with respect to their run number. Each run corresponds to a single heading angle, a single wave height, and a single speed (i.e., each run is a single cell). The data from each available run is used as the SHM data for observed cells. The 57 of the runs tested during the HSV-2 Swift seakeeping trials which reported no technical difficulties and had the t-foil retracted are included as the data set in this paper.

The strain gauge data are converted to stress data for each run (Brady et al. 2004), then windowed and averaged to determine the mean PSD of the cell. Typical runs lasted for around 30 minutes but varied based on changes in wave height. Fig. 4a depicts a five minute portion of the stress time history for Run 185 which is associated with a heading angle of $0^{\circ}$, wave height of 3.3m, and ship speed of 15 knots. The PSD function for each separate window of the time history 
of Run 185 are shown in Fig. 4b, along with the mean PSD. Similarly, the mean PSD function was evaluated for all other runs.

The proposed fitting functions defined in Eqs. (7) and (8) are then fit to the mean PSD through the least squares fitting algorithm available in MATLAB (MathWorks 2013) for all runs. The goodness of fit for select runs is presented in Table 1. The PSD of all windows, the mean PSD, the fitted generalized Pierson-Moskowitz function, and the fitted generalized JONSWAP function for Run 185 for the low frequency response and the high frequency response are shown in Fig. 5 (a) and (b), respectively. Fig. 5 (c) and (d) depicts the same for Run 160 with a heading angle of $315^{\circ}$, wave height of $2.6 \mathrm{~m}$, and ship speed of 30 knots. Similar plots for all other runs can be generated, but are omitted from this paper for brevity. The estimated values for the fitted generalized Pierson-Moskowitz function and the fitted generalized JONSWAP function are listed for Runs 185 and 160 in Table 1.

The fitted generalized JONSWAP function outperforms the fitted generalized PiersonMoskowitz function as indicated in Table 2 with regards to the coefficient of determination $\left(\mathrm{R}^{2}\right)$ value for both the low and high frequency components. The fitted generalized JONSWAP function takes the form of the JONSWAP spectrum, which was developed for seas with fetch limitations, non-fully developed seas, and wave-wave interactions. This spectrum is applicable to the SHM data used in this paper, as evident through the trials in which some runs were denoted as confused and others had recorded swell and wave directions with different periods and heights. Additionally, the peak enhancement factor allows multiple peaks in the response spectrum to be captured as seen in the Fig. 5 (b). Thus, the generalized JONSWAP function can include the high energy content for a broader range of frequencies. 
The proposed fitting functions more accurately fit the response in the zero heading angle case than the non-zero case as shown in Table 1. This can be attributed to the expected form of the linear transfer function for this specific ship. RAOs are ship specific functions. The variability of RAOs with heading angle and wave period differ from vessel to vessel due to the ship length, structural design, and ride characteristics, among others (Hughes 1983; Chan et al. 2002, Salvesen et al. 1970).

In order to investigate the applicability and accuracy of the prediction methodology presented in this paper, observed data from a high speed, high wave height run was omitted from the initial data set; this removed run is referred to as the test point. The remaining data, in each case, is referred to as the available data set. Predicted values for the test point, which are generated from using the available data set, are then compared with the observed data to assess the prediction method. Synthetic test point data is predicted for three cases of available data: (A) No missing data (i.e., all 57 runs are used in the prediction procedure, minus the test point data) (B) $30 \%$ missing data, and (C) 50\% missing data. For this example, the two test points are chosen: Run 185, where the wave height is $3.3 \mathrm{~m}$, the vessel speed is $15 \mathrm{knots}$, and the heading angle is $0^{\circ}$, and Run 160 , with a wave height of $2.6 \mathrm{~m}$, and ship speed of 30 knots and heading angle of $315^{\circ}$.

The mean PSD function calculated for each of the trials in the available data set is fitted with the generalized fitting functions and the fitting parameters are determined for both the low frequency and the high frequency content. The linear surface is developed for the fitting parameters for the generalized JONSWAP function and the generalized Pierson-Moskowitz function independently to predict the test point data. The available data in Case A is shown in Fig. 6 (a) (e) for each of the low frequency fitting parameters, along with the fitting surface for the parameter and the predicted value for the parameter at the test point equivalent to Run 185. Fig. 6 (a) - (e) 
shows the change in the parameters with respect to wave height and vessel speed for a $0^{\circ}$ heading angle. The predicted values for the parameters of the test point are indicated with a star in Fig. 6 (a) - (e). Similar plots for the high frequency parameters are omitted from this paper for brevity, as are the plots for Cases B and C, as well as all plots for the test point equivalent to Run 160.

The estimated value for each of the parameters of the test point are then used to develop the predicted PSD function for the test point. The PSD function for the test point equivalent to Run 185 is shown in Fig. 7(a) and (b) for Case A, Fig. 7(c) and (d) for Case B, and Fig. 7(e) and (f) for Case C. Similar plots for the test point equivalent to Run 160 can be shown but have been omitted for brevity. In each case, the PSDs predicted from the generalized JONSWAP function and the generalized Pierson-Moskowitz function are compared to the observed data for the test point and the mean square error is evaluated and listed in Table 3. The generalized JONSWAP function more accurately predicts the lower and overall PSD; however, the generalized Pierson-Moskowitz function has a lower mean square error in the high frequencies. Accordingly, if the high frequency response (i.e., whipping response) is of interest, then the generalized Pierson-Moskowitz function would provide better prediction of the behavior.

The predicted PSD for the test point is used to generate synthetic time-history data by applying Eqs. (17) - (19). A distribution fitting process is applied to the available SHM data to determine the best fit for the stress distribution. Goodness of fit is judged for the normal, lognormal, and Weibull distribution using the Kolmogorov-Smirnov test (Ang and Tang 2007), as well as probability plots. The statistical analysis of the stress observed at the T2-4 sensor during Runs 185 and 160 are shown in Fig. 8 for the (a) Normal, (b) Lognormal, and (c) Weibull distributions. The analysis shows that the normal distribution is the best fit for the data and that further transformation of the signal is not needed. The resulting synthetic time-history data for the 
T2-4 stress response are shown for Cases A, B, and C in Fig. 9 (a), (b), and (c), respectively, for the test point equivalent to Run 185 . In each plot, the synthetic time histories generated from the generalized JONSWAP function and the generalized Pierson-Moskowitz are plotted against the observed data for Run 185.

In order to estimate the fatigue damage index in the cell, the stress range histogram for the test point are generated through applying the rain-flow counting method (Wirsching and Shehata 1997) to the synthetic time-history data for the T2-4 stress response. Additionally, the spectral based methods for estimating the stress range histogram for narrow band signals (Eq. 12) and wide band processes (Eq.14) are applied. The resulting probability density functions (PDFs) of stress range are shown in Fig. 10 for Cases A, B, and C for the test point equivalent to Run 185. The stress range histogram is estimated from the predicted PSD through the narrow banded approach, broad banded approach, and the cycle-counting method, as applied to the synthetic data generated from the predicted PSD, for the generalized Pierson-Moskowitz function and the generalized JONSWAP function. The stress range PDF is calculated for the recorded SHM for the test point equivalent to Run 185 and is shown as the observed curve in each of the plots of Fig. 10.

In Cases A, B, and C, the mean and standard deviation of the stress range is most accurately predicted through the cycle counting method in the time domain for the synthetic data generated from the predicted PSD with the generalized Pierson-Moskowitz fitting function, as shown in Table 4. For the test point equivalent to Run 185 , the mean stress ranges is predicted to within $7 \%$ error for all cases of missing data when using the cycle-counting methods as applied to the synthetic data generated from the predicted Pierson-Moskowitz PSD; the standard deviation is predicted within $8 \%$ error for all cases of missing data. The better performance of the predicted Pierson-Moskowitz PSD can partially be attributed to the contribution of the high frequency 
component of the response to the stress range and subsequent fatigue damage. Similarly, the stress range parameters are most accurately predicted through the cycle counting method applied to the synthetic data generated from the predicted PSD with the generalized Pierson-Moskowitz fitting function for the test point equivalent to Run 160, as indicated in Table 5.

Given the location of the T2-4 sensor on the aluminum HSV2-Swift, the mean of the logarithm of fatigue coefficient, $A$ for the structural detail is 11.47 and the slope of the S-N line in logarithm scale, $m$, is 3.37 (Collette and Incecik 2006; Tveiten 1999). Annual fatigue damage accumulation indices are calculated by assuming an operational rate of $2 / 3$ (i.e., it is assumed that the ship is active for a total time of $2 / 3$ of a year) and Eqs. (10) and (11). Table 6 lists the annual damage index predicted for the test point using the synthetic data generated from the predicted PSD with the generalized Pierson-Moskowitz fitting function for Cases A, B, and C. Values for the annual damage index estimated from the observed SHM data for the test point are also included. The accuracy of the approach is dependent on the available data as shown in Table 6 for Cases A, B and C for both for the test point equivalent to Run 185 and Run 160. The damage index predicted for the test point for Case A is the most accurate, due to the larger set of available SHM data. The larger set of available data has a reduced dependency on a small number of individual runs which may have experienced technical malfunctions.

\section{Conclusion}

This paper proposed a methodology to predict the structural response of ship hulls based on SHM. The proposed approach estimates the structural response of ship hulls in operational conditions which are not included in the SHM dataset. The SHM data is discretized into stationary cells in terms of the vessel speed, heading angle, and wave height. In general, SHM data populates only a portion of the potential operating conditions for the vessel, but includes essential information on 
the as-built condition of the structure and the actual loads acting on the structure which can reduce the epistemic uncertainty in the structural assessment of the ship. However, in order to assess the long term hull performance, structural response in all cells must be known. The proposed methodology fits SHM data with generalized fitting functions and then estimates the response in unobserved cells (i.e., operating conditions). The approach predicts the PSD and time domain response in unobserved cells and is capable of developing a full set of data to enable spectral and time based fatigue life estimation approaches. The following conclusions are drawn:

- The proposed method can predict the structural response in an unobserved cell. This allows essential information regarding the as-built condition and the actual loads acting on the structure, normally captured in the SHM data, to be integrated into the fatigue life prediction.

- The PSD functions of ship SHM data can be fitted with the generalized JONSWAP function and the generalized Pierson-Moskowitz function proposed in this paper. The aforementioned functions fit the observed SHM data but are most applicable to the responses observed for a $0^{\circ}$ heading angle for the HSV-2 Swift. While this may vary from ship to ship, the consideration of both the low frequency and high frequency when predicting the PSD in unobserved cells is shown to be critical to estimating the fatigue damage.

- By predicting the PSD functions for unobserved cells, both time domain and spectral based methods can be employed to estimate the fatigue damage accumulation. Additionally, the proposed method distinguishes between the low and high frequency content of the signal and predicts the PSD in unobserved cells accordingly. The accuracy of the predicted values, however, vary with the availability of data. The results from the illustrative example 
indicate that the proposed approach can predict, for head sea condition and speed 15knots, the mean and standard deviation of the stress range within $7 \%$ and $8 \%$ error, respectively, using the data generated from the fitted Pierson-Moskowitz PSD.

- With the observed SHM data for the stress response found to be Gaussian, synthetic data for unobserved cells is generated by simulating an instance of the random process from the predicted PSD. For the application in this paper, stress time histories were used as the SHM data. If, however, strain time histories were used, the synthetic strain data could further be used in nonlinear fatigue crack growth analysis.

- Further research into the form of the surface used to predict the unobserved data is necessary and should account for the variations of vertical bending response with changes in wave height, heading angle, and ship speed.

\section{Acknowledgements}

The support by grants from (a) the National Science Foundation (NSF) Award CMMI-1537926, (b) the U.S. Office of Naval Research (ONR) Awards N00014-08-1-0188, N00014-12-1-0023, and N00016-1-2299, and (c) the National Aeronautics and Space Administration (NASA) Award NNX10AJ20G is gratefully acknowledged. The opinions presented in this paper are those of the authors and do not necessarily reflect the views of the sponsoring organizations.

\section{References}

Aalberts, P. J., Nieuwenhuijs, M. W., 2006. Full scale wave and whipping induced hull girder loads. In: Proc., 4th. Int. Conf. on Hydroelasticity, Wuxi, China.

Ang, A.H-S., Tang, W.H., 2007 Probability concepts in engineering: emphasis on applications to civil and environmental engineering. $2^{\text {nd }}$ edition, Wiley and Sons, New York, USA

Benasciutti, D., Tovo, R., 2007. On fatigue damage assessment in bimodal random processes. Int. J. Fatigue, 29(2), 232-244. 
Bendat, J., 1964. Probability functions for random responses prediction for peaks, fatigue damage, and catastrophic failures. Vol. 33. National Aeronautics and Space Administration, 1964.

Brady, T., Bachman, R., Donnelly, M., Griggs, D., 2004. HSV-2 Swift instrumentation and technical trials plan. Naval Surface Warfare Center, Carderock Division (NSWCCD), West Bethesda, Maryland.

Butler, R. W., Machado, U. B., Rychlik, I., 2009. Distribution of wave crests in a non-Gaussian sea. Appl. Ocean Res., 31(1), 57-64.

Chan, H.S., Atlar, M. and Incecik, A., 2002. Large-amplitude motion responses of a Ro-Ro ship to regular oblique waves in intact and damaged conditions. Journal of marine science and technology, 7(2), 91-99.

Chang, P. C., Flatau, A., Liu, S., 2003. Review paper: health monitoring of civil infrastructure. Structural Health Monitoring, 2(3), 257-267.

Collette, M. and Incecik, A., 2006. An approach for reliability-based fatigue design of welded joints on aluminum high-speed vessels. Journal of ship research, 50(1), 85-98.

Dirlik, T., 1985. Application of computers in fatigue analysis. Ph.D. thesis, University of Warwick, Coventry, England.

DNV, 2010. Fatigue methodology of offshore ships, Det Norske Veritas Classification, Høvik, Norway.

Eurocode 9, 2009. Design of aluminum structures part 1-3, additional rules for structures susceptible to fatigue, CEN - European Committee for Standardization, Brussels, Belgium.

Hasselmann, K., Barnett, T., Bouws, E., Carlson, H., Cartwright, D., Enke, K., Ewing, J., Gienapp, H., Hasselmann, D., Kruseman, P., 1973. Measurements of wind-wave growth and swell decay during the Joint North Sea Wave Project (JONSWAP), Deutches Hydrographisches Institut.

Herszberg, I., Li, H., Dharmawan, F., Mouritz, A., Nguyen, M., Bayandor, J., 2005. Damage assessment and monitoring of composite ship joints. Compos. Struct., 67(2), 205-216.

Hodapp, D. P., Collette, M. D., Troesch, A. W., 2015. Stochastic nonlinear fatigue crack growth predictions for simple specimens subject to representative ship structural loading sequences. Int. J. Fatigue, 70, 38-50.

Hughes, O.F., 1983. Ship structural design: a rationally-based, computer-aided, optimization approach. Wiley-Interscience.

Jensen, J. J., Dogliani, M., 1996. Wave-induced ship full vibrations in stochastic seaways. Mar. Struct., 9(3), 353-387.

Kahma, K., Pettersson, H., and Tuomi, L., 2003. Scatter diagram wave statistics from the northern Baltic Sea. MERI-Report Series of the Finnish Institute of Marine Research, 49, 15-32.

Kim, C.H., 2008. Nonlinear waves and offshore structures (Vol. 27). World Scientific.

Komen, G., Hasselmann, K., Hasselmann, K., 1984. On the existence of a fully developed windsea spectrum." J. Phys. Oceanogr., 14(8), 1271-1285. 
Ling, Y., Shantz, C., Mahadevan, S., Sankararaman, S., 2011. Stochastic prediction of fatigue loading using real-time monitoring data. Int. J. Fatigue, 33(7), 868-879.

Liu, Y., Nayak, S., 2012. Structural health monitoring: state of the art and perspectives. JOM, 14.

Lohninger, H., 1999. Teach/me: data analysis. Springer-Verlag, Berlin-New York-Tokyo,

Lutes, L. D., Larsen, C. E., 1990. Improved spectral method for variable amplitude fatigue prediction. J. Struct. Eng., 116(4), 1149-1164.

Lynch, J. P., Loh, K. J., 2006. A Summary review of wireless sensors and sensor networks for structural health monitoring. Shock Vib. Dig., 38(2), 91-130.

Mao, W., Ringsberg, J. W., Rychlik, I., Storhaug, G., 2010. Development of a fatigue model useful in ship routing design. J. Ship Res., 54(4), 281-293.

MathWorks. 2013. Curve fitting toolbox user's guide. The Math Work, Inc. Natick, MA,USA

McCarthy, J. J., 2001. Climate change 2001: Impacts, adaptation, and vulnerability: Contribution of working group II to the third assessment report of the intergovernmental panel on Climate Change. Cambridge University Press.

Naess, A., Moan, T., 2012. Stochastic dynamics of marine structures, Cambridge University Press.

Nichols, J.M., Fackler, P.L., Pacifici, K., Murphy, K.D., Nichols, J.D., 2014. Reducing fatigue damage for ships in transit through structured decision making. Marine Structures, 38, 1843.

Ochi, M.K., 1978. Wave statistics for the design of ships and ocean structures (Paper No. 2). SNAME Transactions, 86, 47-76.

Okasha, N. M., Frangopol, D. M., Decò, A., 2010. Integration of structural health monitoring in life-cycle performance assessment of ship structures under uncertainty. Mar. Struct., 23(3), 303-321.

Okasha, N.M., Frangopol, D.M., Saydam, D. and Salvino, L.W., 2011. Reliability analysis and damage detection in high-speed naval craft based on structural health monitoring data. Struct. Health Monit., 10(4), 361-379.

Osborne, A.R., 2010. Nonlinear Ocean Waves and the Inverse Scattering Transform, Int. Geophys. Ser, 97.

Pierson Jr, W. J., Moskowitz, L., 1963. A Proposed spectral form for fully developed wind seas based on the similarity theory of SA Kitaigorodskii. J. Geophys. Res., 69(24), 5181-5190.

Posenato, D., Kripakaran, P., Inaudi, D., Smith, I. F., 2010. Methodologies for model-free data interpretation of civil engineering structures. Comput. Struct., 88(7), 467-482.

Reed, H., Earls, C., 2015. Stochastic identification of the structural damage condition of a ship bow section under model uncertainty. Ocean Eng., 103, 123-143.

Salvesen, N., Tuck, E.O. and Faltinsen, O., 1970. Ship motions and sea loads. Trans. SNAME, 78(8), 250-287.

Shinozuka, M., Deodatis, G., 1991. Simulation of stochastic processes by spectral representation Appl. Mech. Rev., 44(4), 191-204. 
Sielski, R. A., Nahshon, K., Salvino, L. W., Anderson, K., Dow, R., 2013. The ONR ship structural reliability program. Nav. Eng. J., 125(4), 61-84.

Sielski, R. A., 2012. Ship structural health monitoring research at the Office of Naval Research. JOM, 64(7), 823-827.

Sikora, J. P., Michaelson, R. W., Ayyub, B. M., 2002. Assessment of cumulative lifetime seaway loads for ships. Nav. Eng. J., 114(2), 167-180.

Sikora, J. P., 1998. Cumulative lifetime loadings for naval ships. ASME-Publications-AD, 56, 299-312.

Sikora, J.P., Dinsenbacher, A., Beach, J.E., 1983. A Method for estimating lifetime loads and fatigue lives for swath and conventional monohull ships. Nav. Eng. J. 95(3), 63-85.

Soliman, M., Barone, G., Frangopol, D. M., 2015. Fatigue reliability and service life prediction of aluminum naval ship details based on monitoring data. Struct. Health Monit., 14(1), 3-19.

Tuitman. J.T., 2010. Hydro-elastic response of ship structures to slamming induced whipping. Ph.D. thesis, Dept. of Marine and Transport Technology, Delft University of Technology, Delft, Netherlands

Tveiten, B.W., 1999. Fatigue assessment of welded aluminium ship details. Norwegian University of Science and Technology, Faculty of Marine Technology, Department of Marine Structures.

Vanik, M. W., Beck, J., Au, S., 2000. Bayesian probabilistic approach to structural health monitoring. J. Eng. Mech., 126(7), 738-745.

Wirsching, P., Shehata, A. M., 1977. Fatigue under wide band random stresses using the rain-flow method. J. of Eng. Mater. Technol., 99(3), 205-211.

Zárate, B., Caicedo, J., Yu, J., Ziehl, P., 2012. Probabilistic prognosis of fatigue crack growth using acoustic emission data. J. Eng. Mech., 138(9), 1101-1111.

Zhu, J., 2014. Life cycle fatigue management for high-speed vessel using Bayesian updating approaches. Ph.D. thesis, Dept. of Naval Architecture and Marine Engineering, University of Michigan, Michigan, USA 


\section{Figure Captions}

Figure 1: Fitted extrapolation functions for (a) linear and (b) quadratic fit forms using 100 percent of available data (all data points shown) and 50 percent of the available data (only the lightly colored data points).

Figure 2: Logical scheme for the prediction of the structural response of a naval vessel based on available SHM data.

Figure 3: Structural detail for T2-4 sensor at the keel-to-frame connection on the HSV2-Swift.

Figure 4: Stress time history and PSD function for T2-4 sensor during Run 185.

Figure 5: Low Frequency and high frequency content of the stress time history for T2-4 sensor during Run 185 and Run 160 and the fitted generalized Pierson-Moskowitz function and the fitted generalized JONSWAP function for the mean PSD.

Figure 6: Linear extrapolation functions based on the available data (shown as black points) and the estimated value for the test point for the low frequency generalized PiersonMoskowitz function (a) $A_{L F}$ and (b) $B_{L F}$, and the low frequency generalized JONSWAP function (c) $C_{L F}$, (d) $D_{L F}$, and (e) $E_{L F}$ for the test point equivalent to Run 185.

Figure 7: Extrapolated power spectral density functions for (a) Case A, (b) Case B, and (c) Case $\mathrm{C}$ and the observed PSD for the test point equivalent to Run 185 including both the low frequency and high frequency components.

Figure 8: Fitting results for the stress distribution observed at the T2-4 sensor during Runs 185 and 160 for the (a) Normal, (b) Lognormal, and (c) Weibull distributions.

Figure 9: Generated random processes based on the extrapolated PSD for (a) Case A, (b) Case B, and (c) Case C that are the synthetic SHM data for the test point equivalent to Run 185.

Figure 10: Stress range histograms for (a) Case A, (b) Case B, and (c) Case C estimated using cycling counting methods, the narrow band approximation, and the wide band approximation for the test point equivalent to Run 185 . 


\section{$0^{\circ}$ HEADING ANGLE}
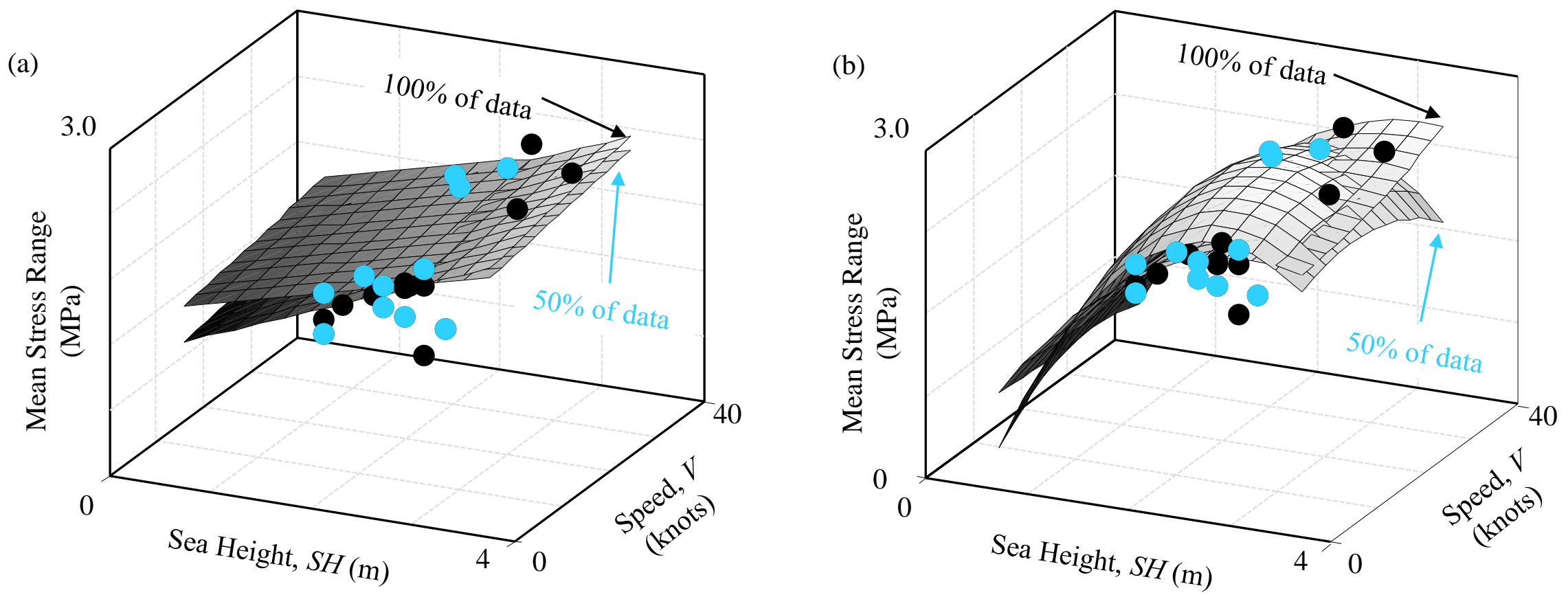


\begin{tabular}{|c|c|}
\hline \multicolumn{2}{|c|}{ Observe SHM data } \\
\hline Time histories responses & Cell Information: \\
Record strain data & Heading Angle, $\alpha$, Ship Speed, \\
Convert strains to stresses, $\sigma(t)$ & $V$, and Sea Wave Height, $S H$ \\
\hline
\end{tabular}

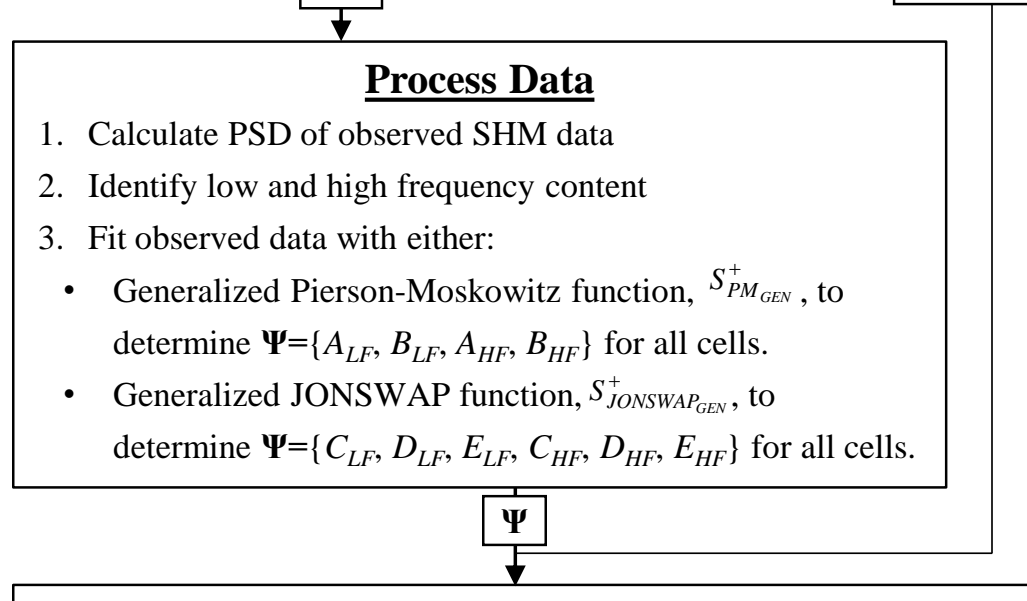

\section{Prediction of Unobserved Response}

1. Estimate $\mathrm{P}_{1, \mathrm{i}}, \mathrm{P}_{2, \mathrm{i}}$, and $\mathrm{P}_{3, \mathrm{i}}$ through a least squares fitting using observed values for $\alpha, V$, and $S H$ for all $\Psi_{i} \in \Psi$.

2. Predict $\Psi_{i}$ for unobserved cells $\Psi_{i}=\mathrm{P}_{1, \mathrm{i}} S H+\mathrm{P}_{2, \mathrm{i}} V+\mathrm{P}_{3, \mathrm{i}} \alpha$ for all $\Psi_{i} \in \boldsymbol{\Psi}$ and develop $\operatorname{PSD}(\omega)$.

$\mid \begin{aligned} & \text { Generate time-history resp } \\ & \text { for unobserved cells, } x(t)\end{aligned}$
une Assessment
mproximate method $(P S D)$

1. Narrow banded approximate method (PSD)

2. Wide banded approximate method (PSD)

3. Cycle counting methods $(x(t))$ 
Figure 03

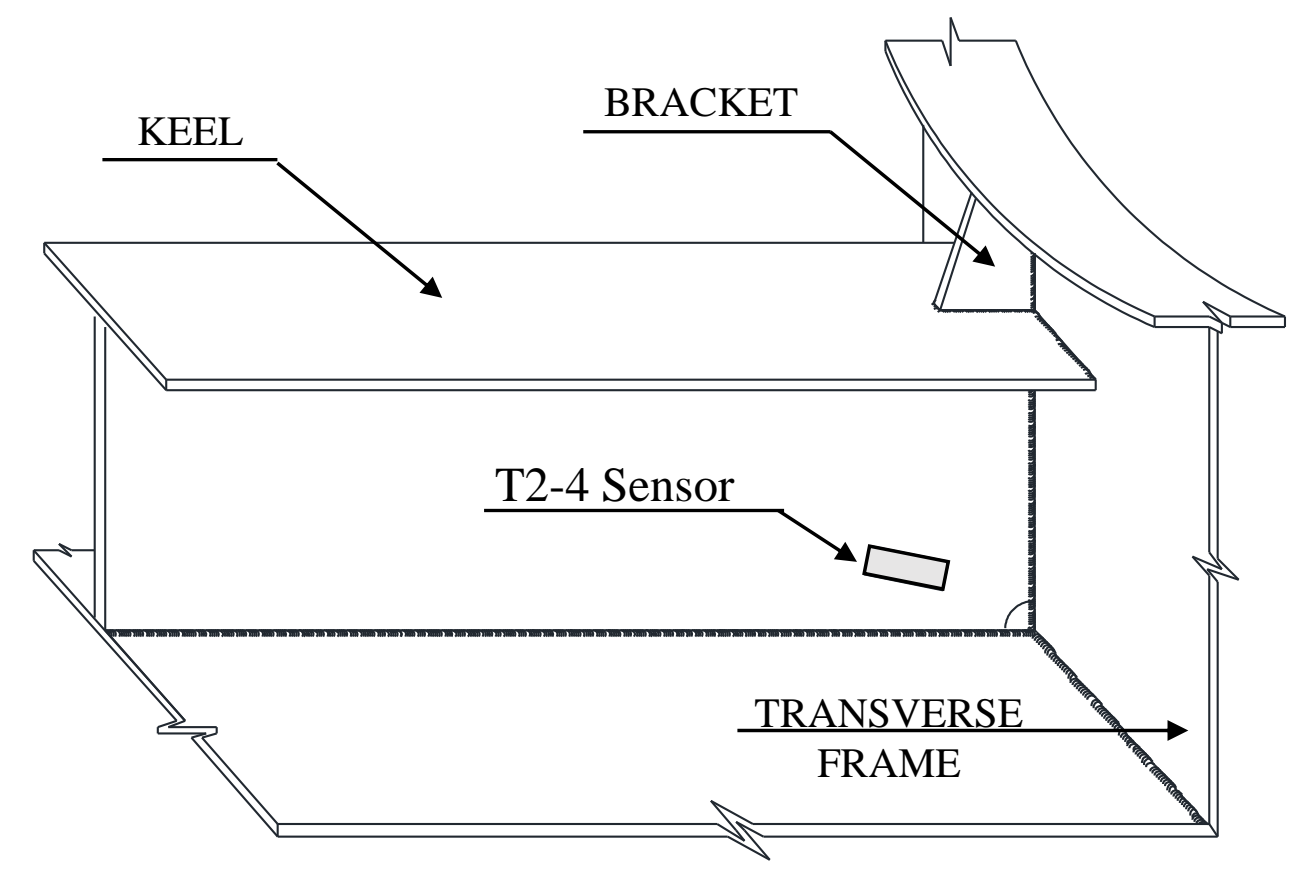


(a)

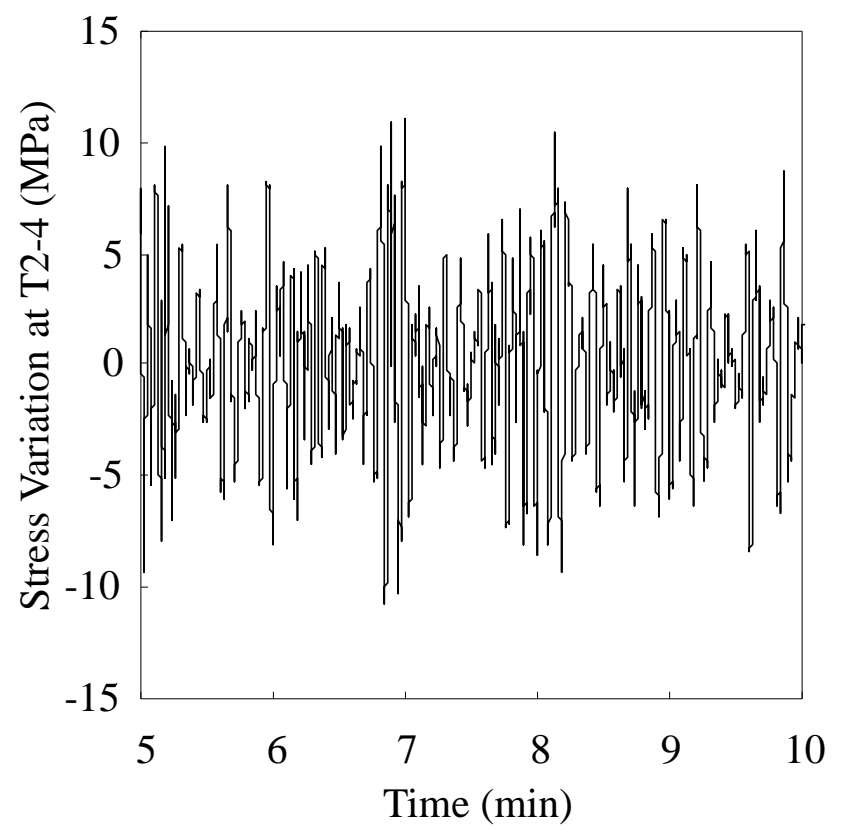

(b)

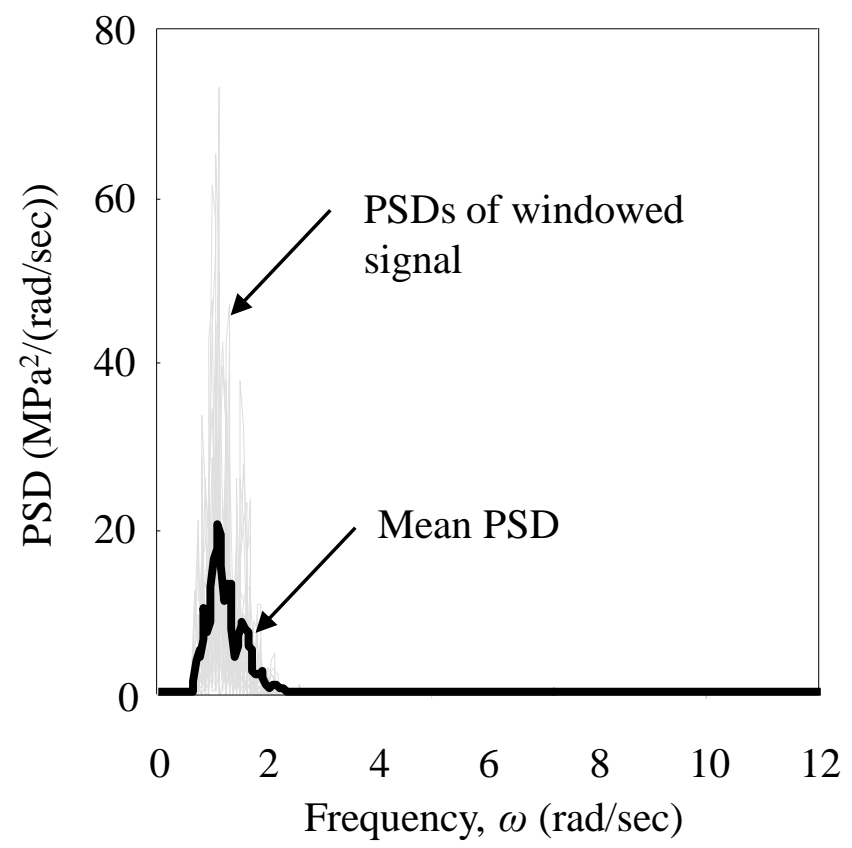


(a)

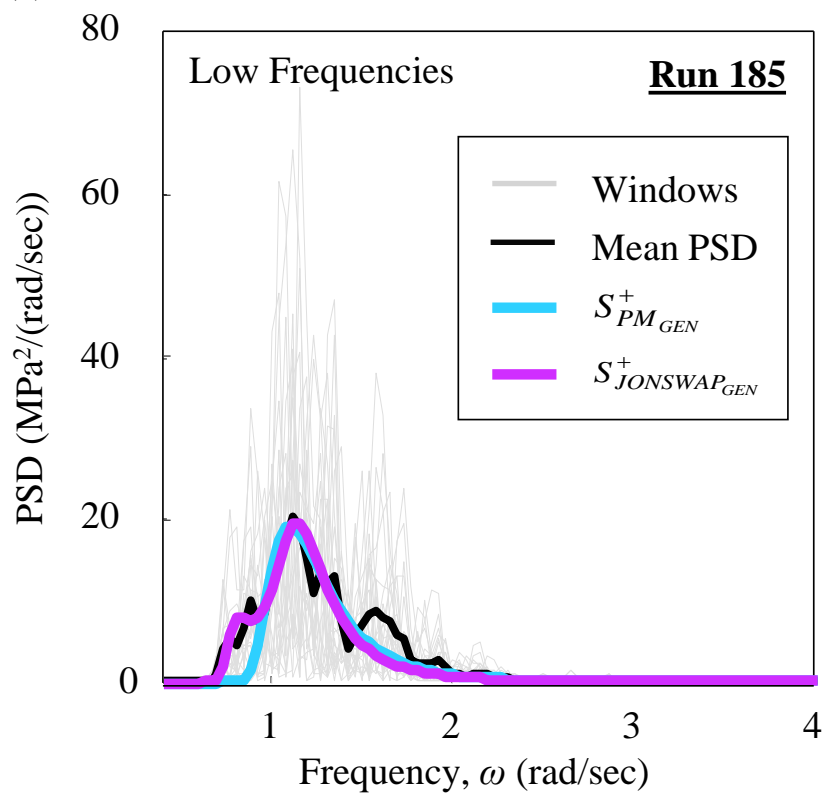

(c)

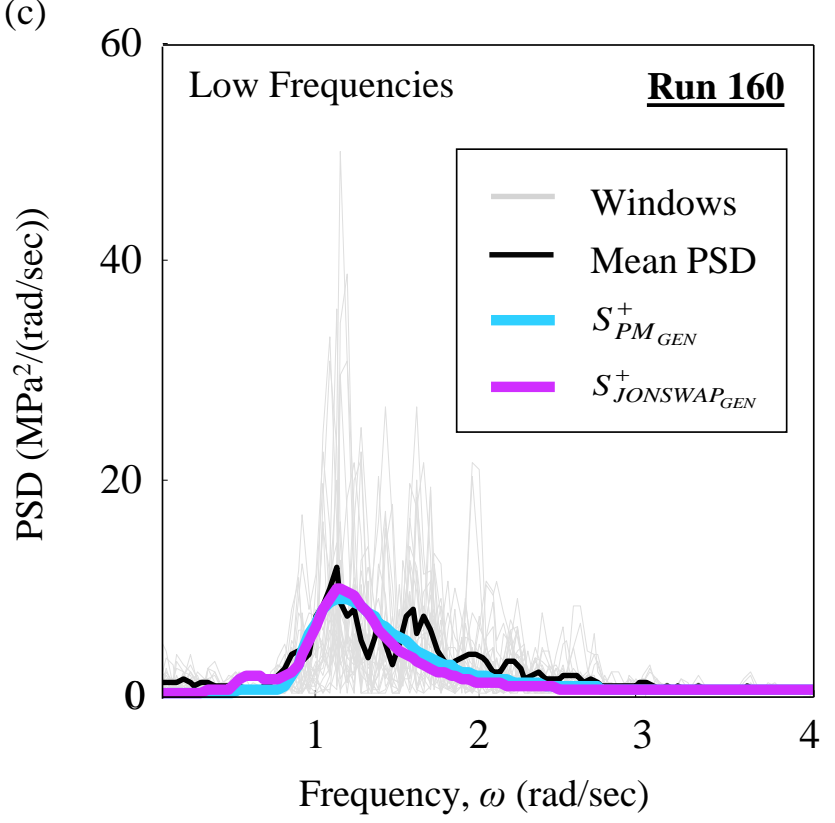

(b)
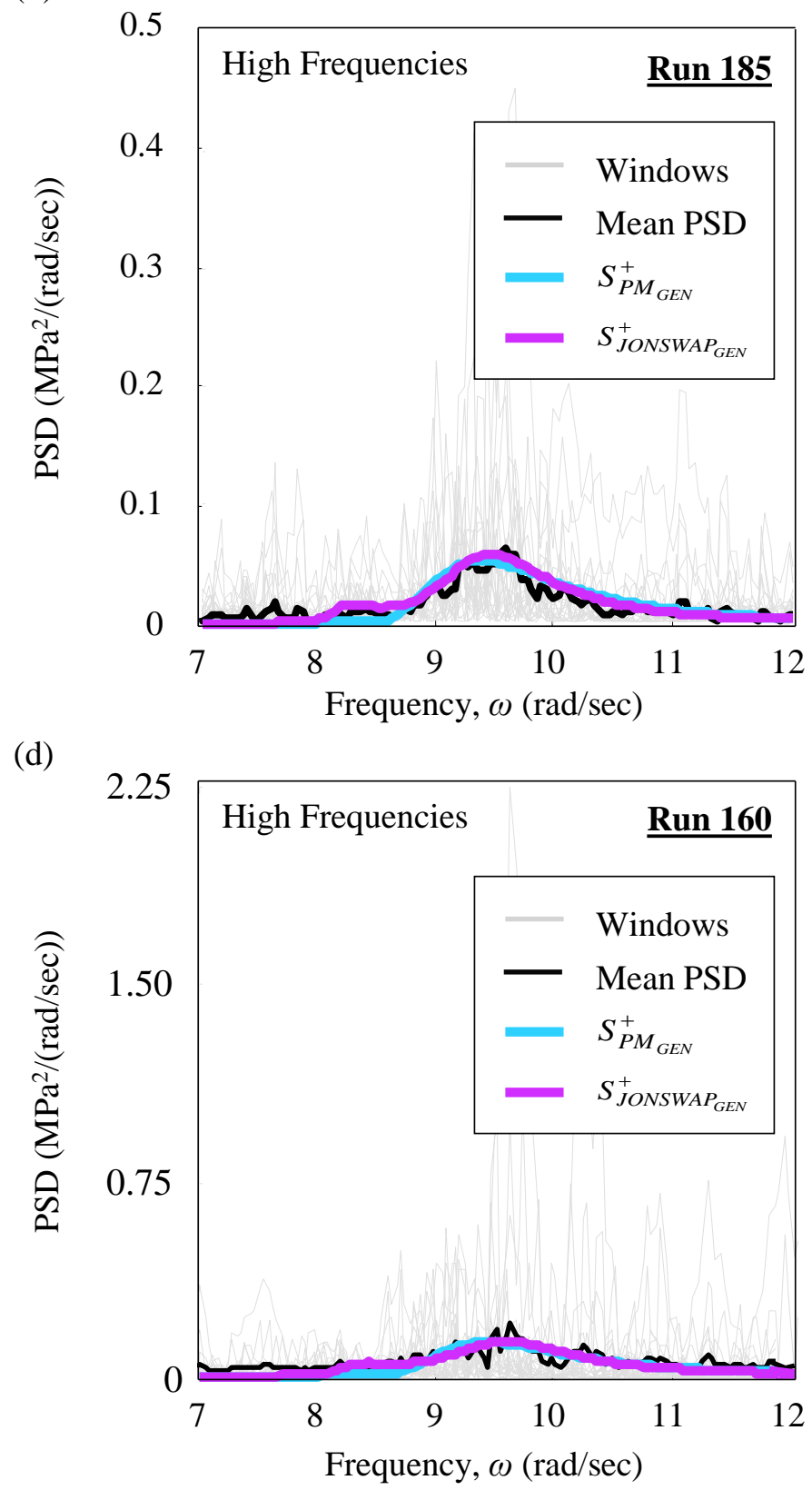


\section{$\underline{0^{\circ} \text { HEADING ANGLE }}$}
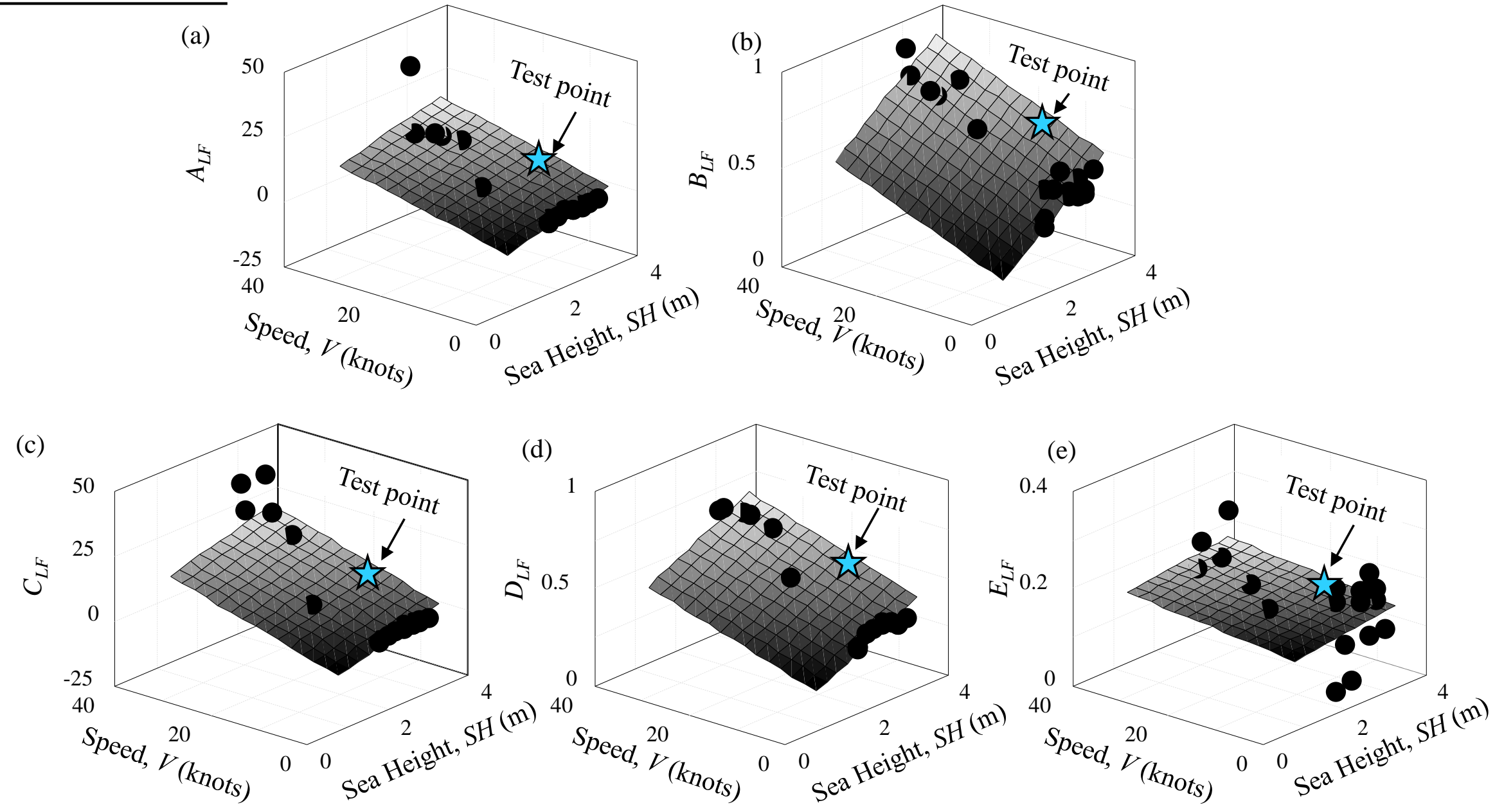


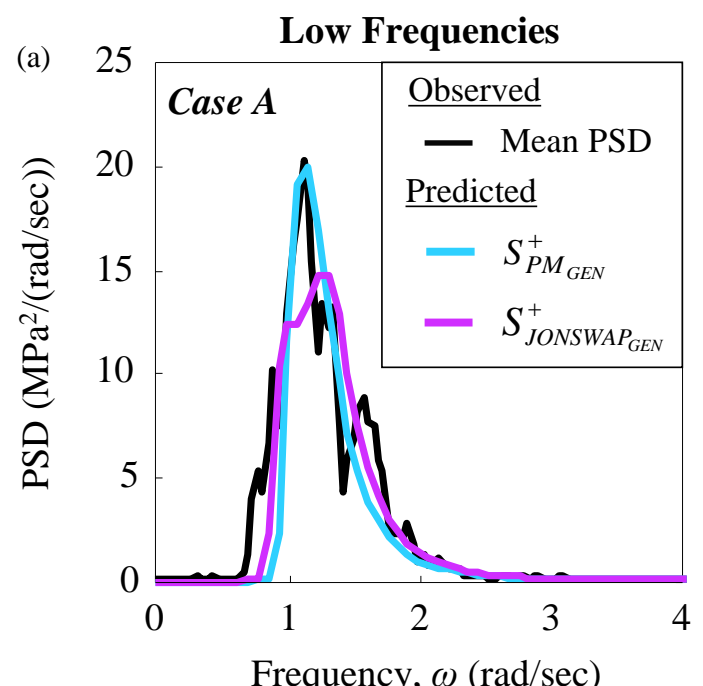

(b)
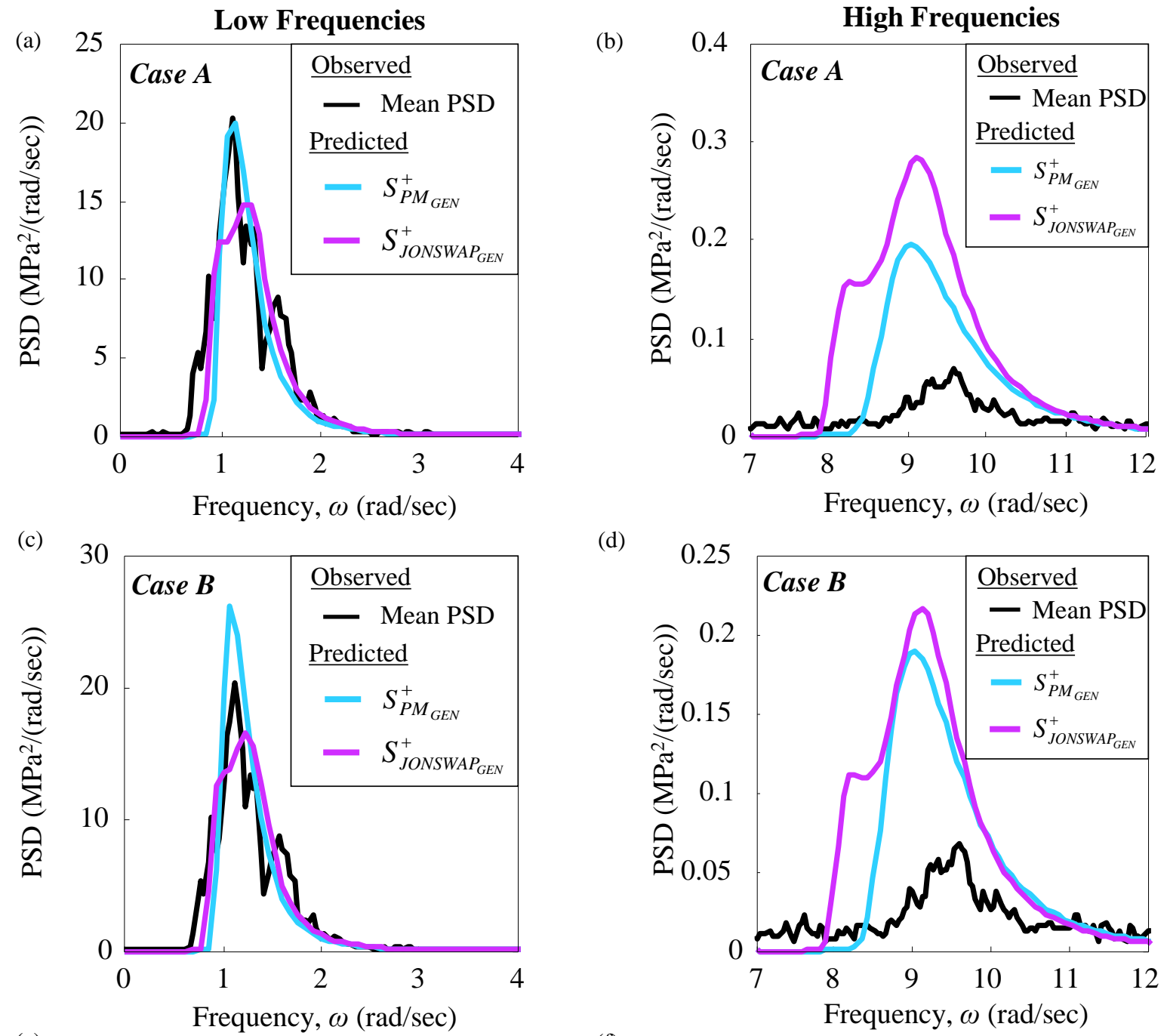

(d)
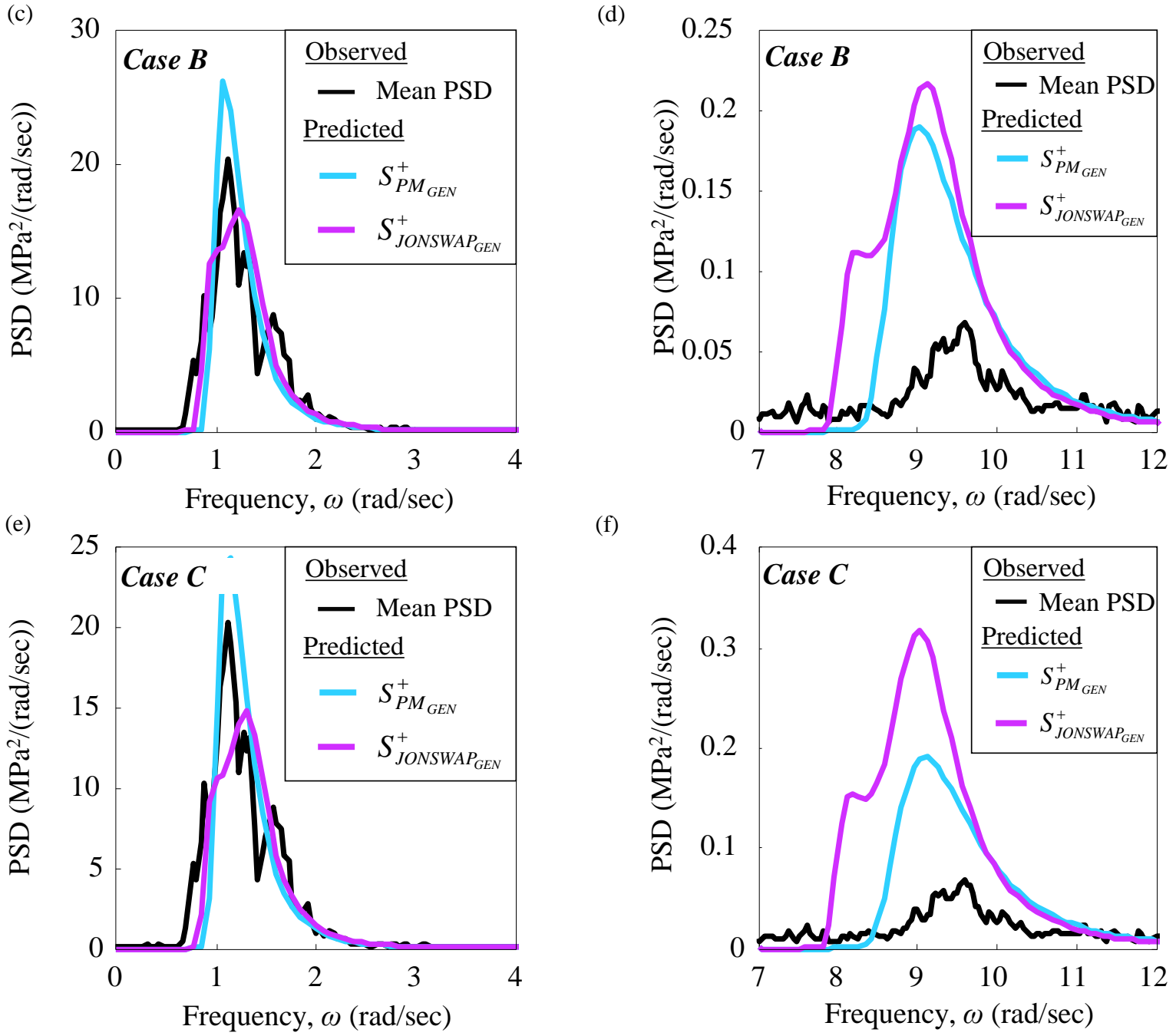

(f)

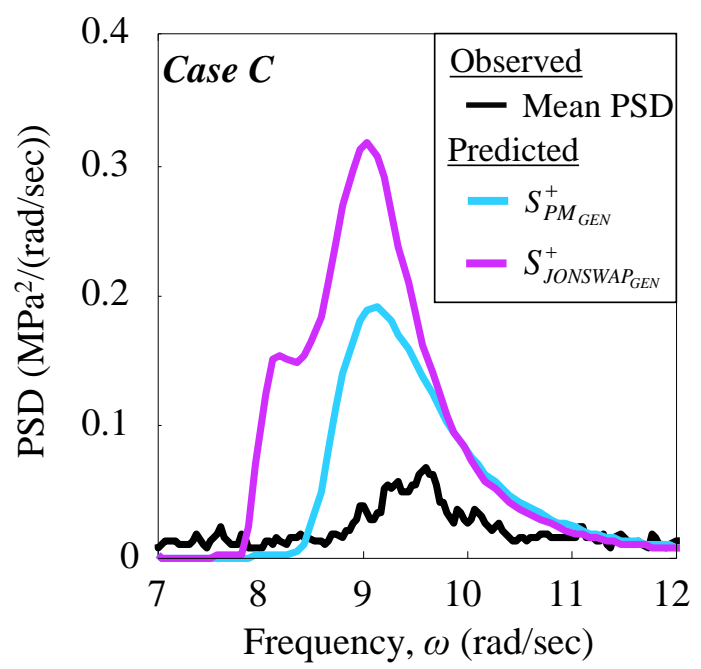



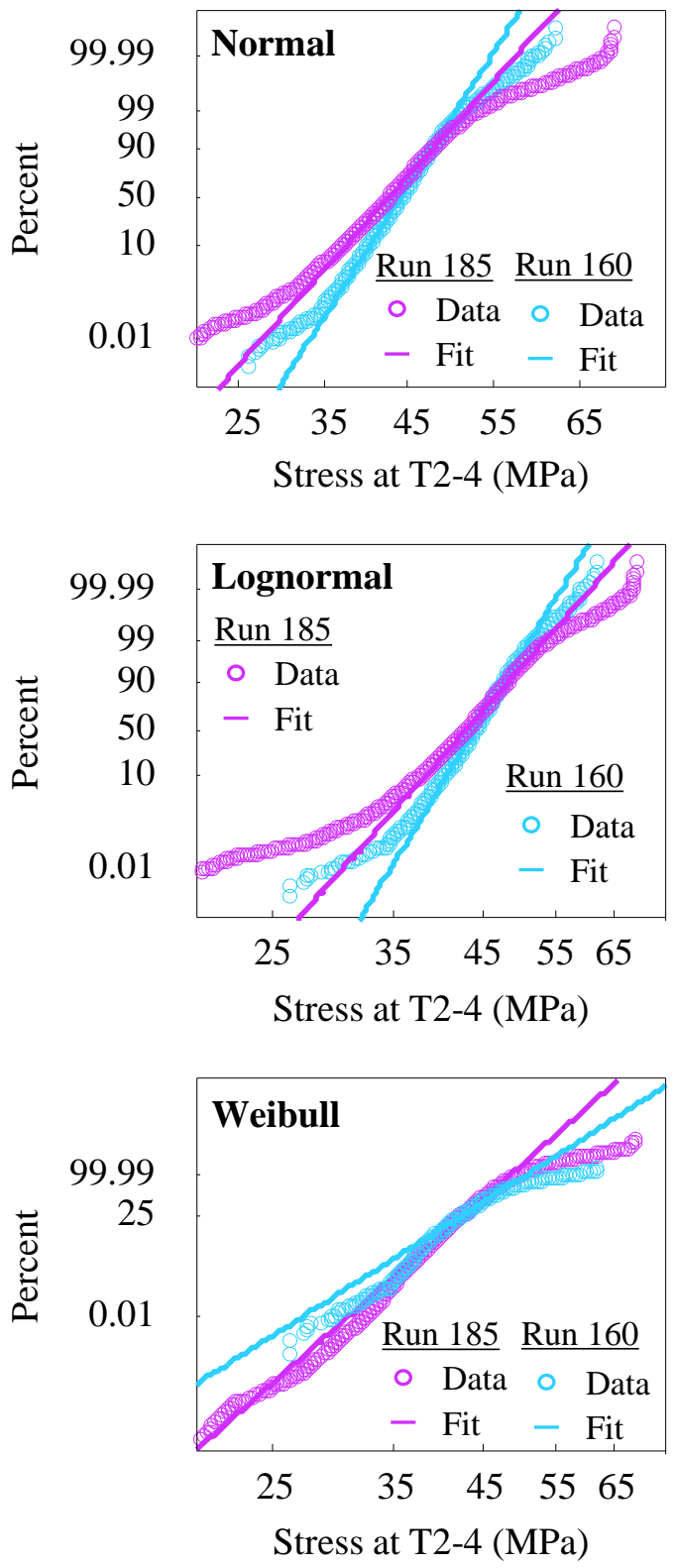


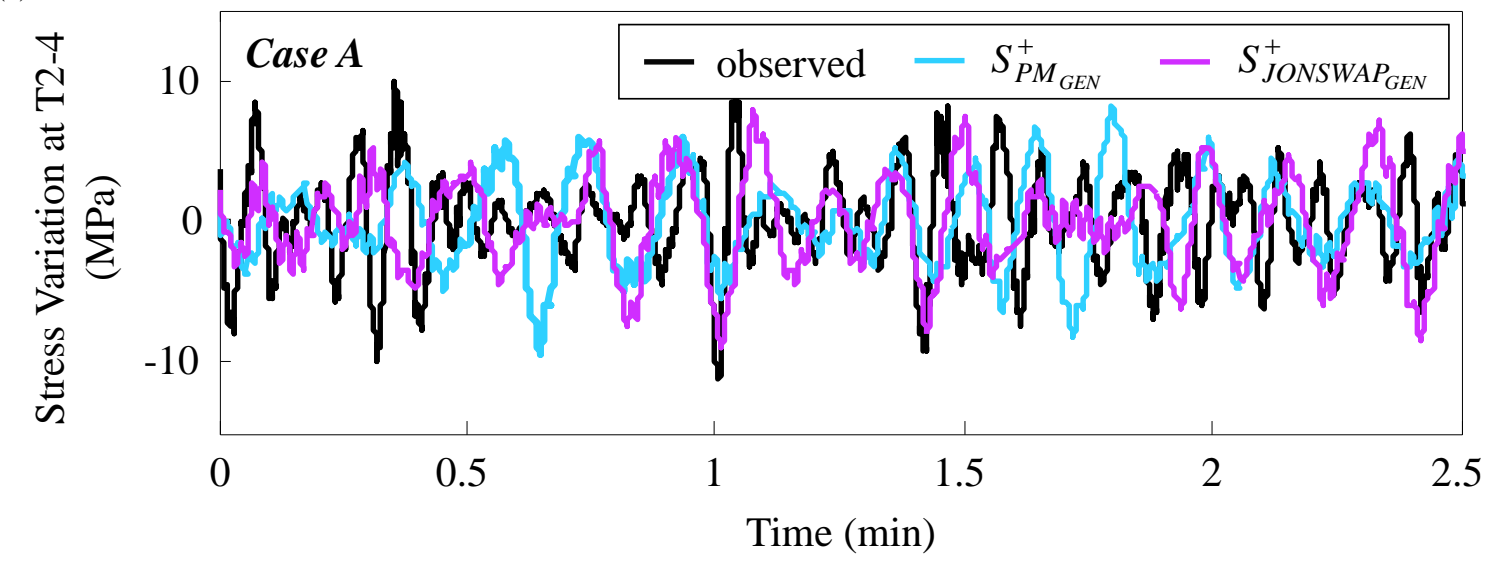

(b)
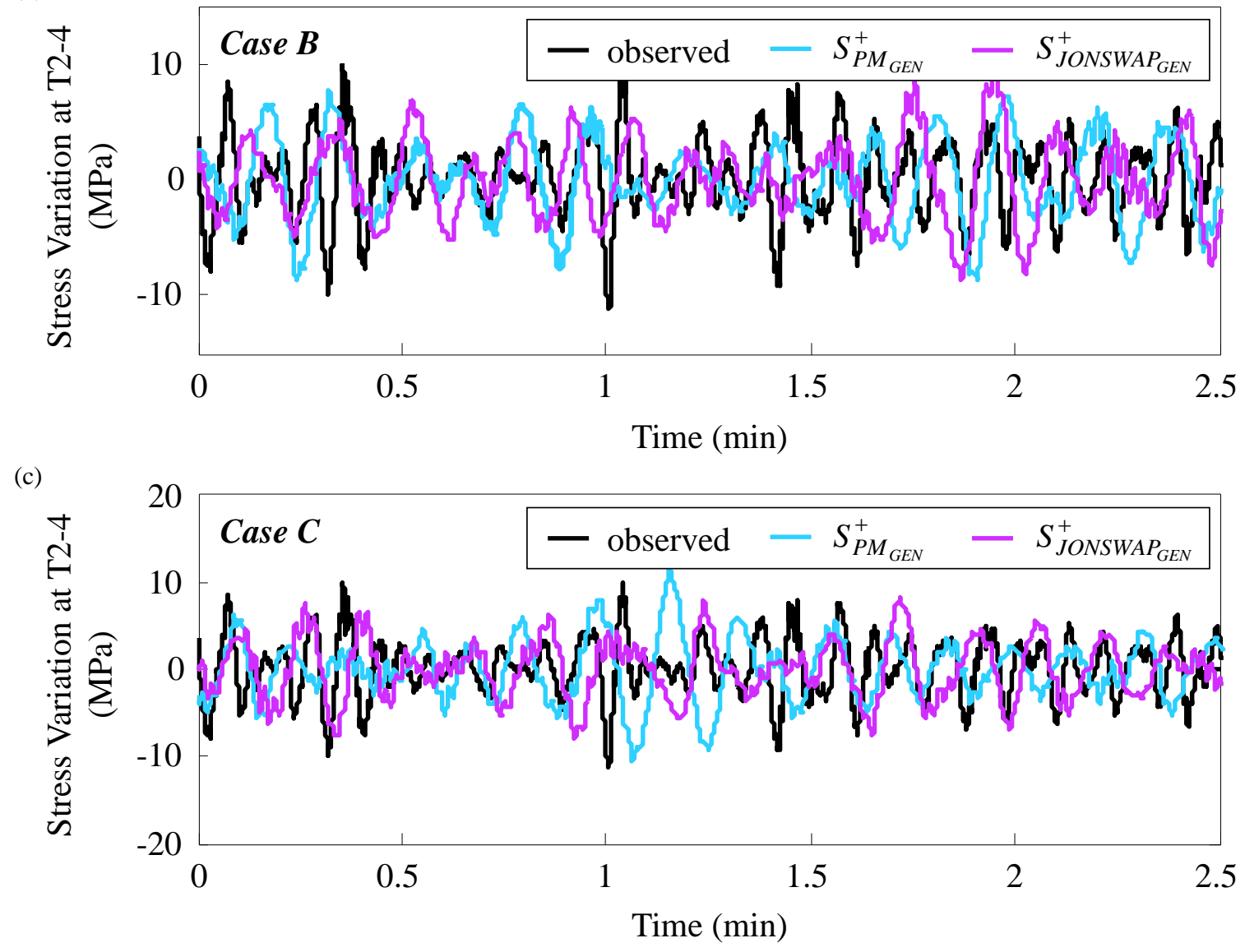

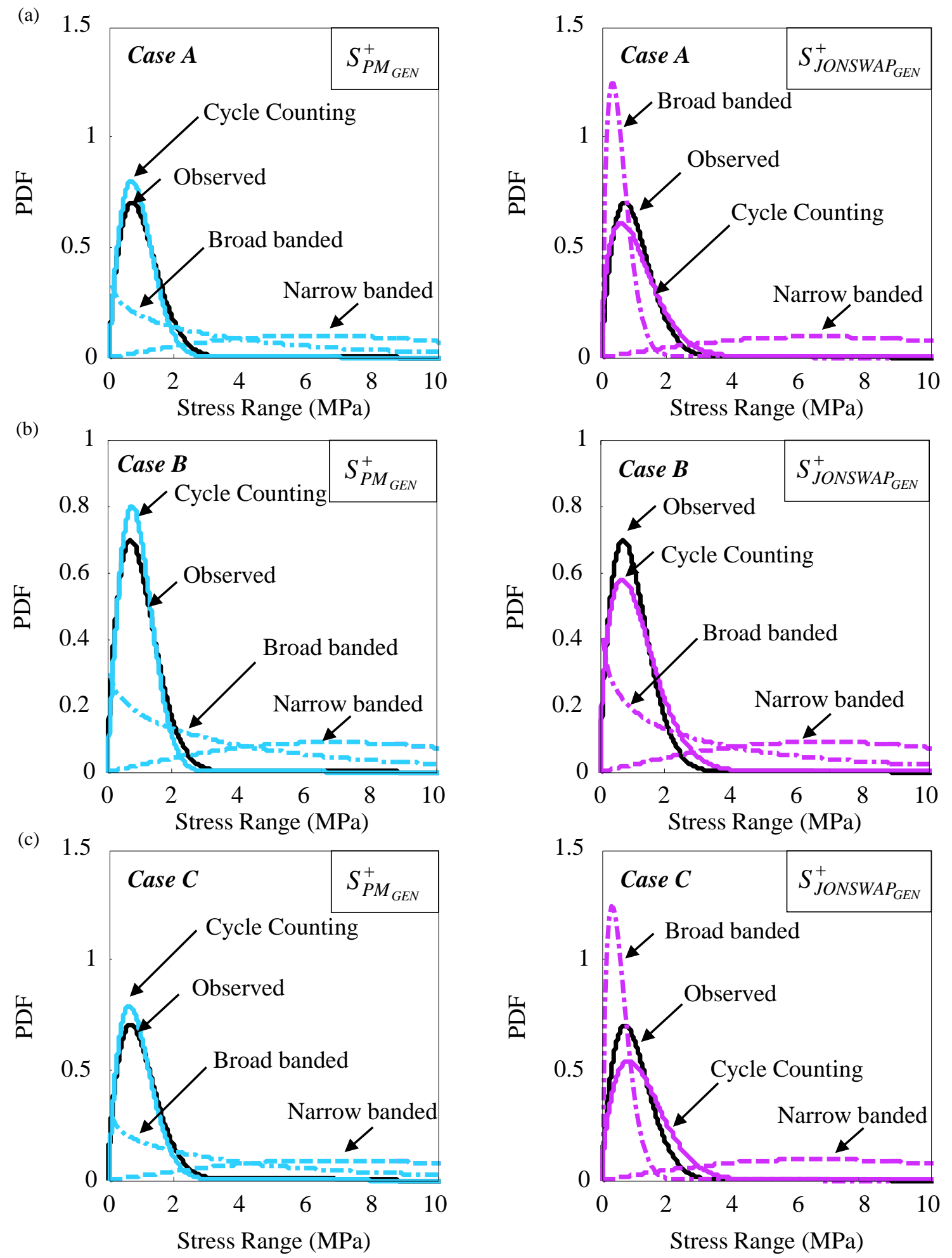
Table 1. Comparison of results for select runs with different heading angles, wave heights, and speeds.

\begin{tabular}{c|c|c|c|c|c|c|c}
\hline \multirow{2}{*}{ Run } & \multirow{2}{*}{$\begin{array}{c}\text { Wave } \\
\text { Height } \\
(\mathbf{m})\end{array}$} & \multirow{2}{*}{$\begin{array}{c}\text { Speed } \\
(\text { knots) }\end{array}$} & \multirow{2}{*}{$\begin{array}{c}\text { Heading } \\
\text { Angle }\end{array}$} & \multicolumn{4}{|c}{ Coefficient of determination, $\boldsymbol{R}^{2}$} \\
\cline { 5 - 7 } & & & $\begin{array}{c}\text { Low Frequency } \\
\text { Fitted PSD } \\
-\boldsymbol{P M}_{\text {GEN }}\end{array}$ & $\begin{array}{c}\text { Fitted PSD - } \\
\text { JONSWAP }\end{array}$ & $\begin{array}{c}\text { Fitted PSD } \\
-\boldsymbol{P M}_{\text {GEN }}\end{array}$ & $\begin{array}{c}\text { Fitted PSD - } \\
\text { JONSWAP }\end{array}$ \\
\hline 185 & 3.3 & 15 & 0 & 0.942 & 0.945 & 0.873 & 0.907 \\
160 & 2.6 & 30 & 315 & 0.779 & 0.857 & 0.771 & 0.792 \\
127 & 1.5 & 35 & 45 & 0.907 & 0.930 & 0.568 & 0.670 \\
120 & 1.9 & 20 & 90 & 0.825 & 0.932 & 0.541 & 0.764 \\
129 & 1.3 & 35 & 135 & 0.562 & 0.673 & 0.506 & 0.786 \\
189 & 2.7 & 15 & 180 & 0.892 & 0.971 & 0.860 & 0.893 \\
\hline
\end{tabular}


Table 2. Fitting Parameters for the generalized Pierson-Moskovitz and generalized JONSWAP functions for Run 185 and 160.

\begin{tabular}{c|c|c|c|c|c}
\hline \multicolumn{3}{|c|}{ PM $_{G E N}$} & \multicolumn{3}{c}{ JONSWAP } \\
\hline Parameter & Run 185 & Run 160 & Parameter & Run 185 & Run 160 \\
\hline$A_{L F}$ & 9.632 & 7.998 & $C_{L F}$ & 6.939 & 19.115 \\
$B_{L F}$ & 0.677 & 0.747 & $D_{L F}$ & 0.455 & 0.749 \\
$A_{H F}$ & 13.56 & 39.82 & $E_{L F}$ & 0.074 & 0.321 \\
$B_{H F}$ & 2.363 & 2.416 & $C_{H F}$ & 8.983 & 29.522 \\
& & & $D_{H F}$ & 1.515 & 1.628 \\
& & & $E_{H F}$ & 0.041 & 0.068 \\
\hline
\end{tabular}


Table 3. Performance of predicted PSD functions as compared to the observed mean PSD for the equivalent test point.

\begin{tabular}{c|c|c|c|c|c|c|c}
\hline \multirow{2}{*}{$\begin{array}{c}\text { Test } \\
\text { Point }\end{array}$} & \multirow{3}{*}{ Case } & \multicolumn{6}{|c}{ Mean Square Error } \\
\cline { 3 - 8 } & & \multicolumn{2}{|c}{ Predicted PSD - PM } & \multicolumn{2}{c}{ Predicted PSD - JONSWAP } \\
& & $\begin{array}{c}\text { Low } \\
\text { Frequencies }\end{array}$ & $\begin{array}{c}\text { High } \\
\text { Frequencies }\end{array}$ & $\begin{array}{c}\text { All } \\
\text { Frequencies }\end{array}$ & $\begin{array}{c}\text { Low } \\
\text { Frequencies }\end{array}$ & $\begin{array}{c}\text { High } \\
\text { Frequencies }\end{array}$ & $\begin{array}{c}\text { All } \\
\text { Frequencies }\end{array}$ \\
\hline \multirow{2}{*}{ Run } & A & 0.000551 & $2.14 \mathrm{E}-07$ & 0.000267 & 0.000571 & $3.40 \mathrm{E}-07$ & 0.000276 \\
185 & $\mathrm{~B}$ & 0.000979 & $1.92 \mathrm{E}-07$ & 0.000474 & 0.000551 & $2.06 \mathrm{E}-07$ & 0.000267 \\
& $\mathrm{C}$ & 0.000914 & $2.36 \mathrm{E}-07$ & 0.000442 & 0.000690 & $2.66 \mathrm{E}-07$ & 0.000334 \\
\hline \multirow{2}{*}{ Run } & A & 0.005816 & $1.785 \mathrm{E}-06$ & 0.002815 & 0.003469 & $1.80 \mathrm{E}-06$ & 0.001679 \\
160 & $\mathrm{~B}$ & 0.003968 & $1.786 \mathrm{E}-06$ & 0.001921 & 0.003093 & $1.81 \mathrm{E}-06$ & 0.001498 \\
& $\mathrm{C}$ & 0.004849 & $1.791 \mathrm{E}-06$ & 0.002347 & 0.004155 & $1.83 \mathrm{E}-06$ & 0.002012 \\
\hline
\end{tabular}


Table 4. Stress range parameters predicted for the test point equivalent to Run 185.

\begin{tabular}{|c|c|c|c|c|c|c|c|}
\hline \multirow{3}{*}{ Data Source } & \multirow{3}{*}{ Method } & \multicolumn{6}{|c|}{ Stress Range (MPa) } \\
\hline & & \multicolumn{2}{|c|}{ Case A } & \multicolumn{2}{|c|}{ Case B } & \multicolumn{2}{|c|}{ Case $\mathrm{C}$} \\
\hline & & Mean & $\begin{array}{c}\text { Standard } \\
\text { Deviation }\end{array}$ & Mean & $\begin{array}{c}\text { Standard } \\
\text { Deviation }\end{array}$ & Mean & $\begin{array}{c}\text { Standard } \\
\text { Deviation }\end{array}$ \\
\hline Observed Data & Cycle Counting & 1.020 & 0.593 & 1.020 & 0.593 & 1.020 & 0.593 \\
\hline \multirow{3}{*}{$\begin{array}{l}\text { Predicted PSD - } \\
J O N S W A P_{G E N}\end{array}$} & Cycle Counting & 1.276 & 0.717 & 0.889 & 0.483 & 1.613 & 1.048 \\
\hline & Broad Banded & 0.648 & 0.448 & 0.538 & 0.359 & 0.910 & 0.689 \\
\hline & Narrow Banded & 7.239 & 3.778 & 6.964 & 3.640 & 6.598 & 3.447 \\
\hline \multirow{3}{*}{$\begin{array}{l}\text { Predicted PSD - } \\
\qquad P M_{G E N}\end{array}$} & Cycle Counting & 0.945 & 0.558 & 1.069 & 0.627 & 1.034 & 0.641 \\
\hline & Broad Banded & 0.545 & 0.365 & 0.648 & 0.607 & 0.614 & 0.393 \\
\hline & Narrow Banded & 6.329 & 3.309 & 6.391 & 3.337 & 5.805 & 3.034 \\
\hline
\end{tabular}


Table 5. Stress range parameters predicted for the test point equivalent to Run 160 through time domain methods.

\begin{tabular}{|c|c|c|c|c|c|c|c|}
\hline \multirow{3}{*}{$\begin{array}{l}\text { Test } \\
\text { Point }\end{array}$} & \multirow{3}{*}{ Case } & \multicolumn{6}{|c|}{ Stress Range (MPa) } \\
\hline & & \multicolumn{3}{|c|}{ Mean } & \multicolumn{3}{|c|}{ Standard deviation } \\
\hline & & Observed & $\begin{array}{c}\text { Predicted } \\
\text { PSD -PM } \\
G E N\end{array}$ & $\begin{array}{l}\text { Predicted PSD } \\
-J O N S W A P_{G E N}\end{array}$ & Observed & $\begin{array}{c}\text { Predicted } \\
\text { PSD -PM } \\
G E N\end{array}$ & $\begin{array}{l}\text { Predicted PSD } \\
-J O N S W A P_{G E N}\end{array}$ \\
\hline \multirow{3}{*}{ Run 160} & $\mathrm{~A}$ & 0.772 & 1.014 & 1.034 & 0.607 & 0.641 & 0.689 \\
\hline & $\mathrm{B}$ & 0.772 & 0.931 & 1.124 & 0.607 & 0.490 & 0.738 \\
\hline & $\mathrm{C}$ & 0.772 & 1.027 & 1.462 & 0.607 & 0.558 & 1.007 \\
\hline
\end{tabular}


Table 6. Prediction of damage index for the test point.

\begin{tabular}{c|c|c|c|c}
\hline Test Point & Case & $\begin{array}{c}\text { Annual Damage Index } \\
\text { (observed data) }\end{array}$ & $\begin{array}{c}\text { Annual Damage Index } \\
\text { (predicted data*) }\end{array}$ & $\begin{array}{c}\text { Percent } \\
\text { Difference }\end{array}$ \\
\hline \multirow{3}{*}{ Run 185 } & A & 0.0121 & 0.0116 & 4.1290 \\
& B & 0.0121 & 0.0131 & 8.1302 \\
& C & 0.0121 & 0.0141 & 16.2824 \\
\hline \multirow{3}{*}{ Run 160 } & A & 0.0111 & 0.0176 & 58.3489 \\
& B & 0.0111 & 0.0192 & 73.3313 \\
& C & 0.0111 & 0.0189 & 70.6345 \\
\hline
\end{tabular}

*from cycle counting methods applied to predicted PSD - $P M_{G E N}$ 